\title{
Population Structure of Colletotrichum tanaceti in Australian Pyrethrum Reveals High Evolutionary Potential
}

\author{
Ruvini V. Lelwala, ${ }^{1}$ Jason B. Scott, ${ }^{2}$ Peter K. Ades, ${ }^{3}$ and Paul W. J. Taylor ${ }^{1, \dagger}$ \\ ${ }^{1}$ School of Agriculture and Food, Faculty of Veterinary and Agricultural Sciences, University of Melbourne, Victoria, Australia 3010 \\ ${ }^{2}$ Tasmanian Institute of Agriculture, University of Tasmania, Burnie, Tasmania, Australia 7320 \\ ${ }^{3}$ School of Ecosystem and Forest Sciences, University of Melbourne, Victoria, Australia 3010 \\ Accepted for publication 7 June 2019.
}

\begin{abstract}
Colletotrichum tanaceti, the causal agent of anthracnose, is an emerging pathogen of commercially grown pyrethrum (Tanacetum cinerariifolium) in Australia. A microsatellite marker library was developed to understand the spatio-genetic structure over three sampled years and across two regions where pyrethrum is cultivated in Australia. Results indicated that $C$. tanacet $i$ was highly diverse with a mixed reproductive mode; comprising both sexual and clonal reproduction. Sexual reproduction of $C$. tanaceti was more prevalent in Tasmania than in Victoria. Little differentiation was observed among field populations likely due to isolation by colonization but most of the genetic variation was occurring within populations. C. tanaceti was likely to have had a long-distance gene and genotype flow among distant populations within a
\end{abstract}

ABSTRACT state and between states. Anthropogenic transmission of propagules and wind dispersal of ascospores are the most probable mechanisms of longdistance dispersal of $C$. tanaceti. Evaluation of putative population histories suggested that $C$. tanaceti most likely originated in Tasmania and expanded from an unidentified host onto pyrethrum. Victoria was later invaded by the Tasmanian population. With the mixed mode of reproduction and possible long-distance gene flow, C. tanaceti is likely to have a high evolutionary potential and thereby has ability to adapt to management practices in the future.

Keywords: Colletotrichum tanaceti, evolutionary potential, population structure, pyrethrum
Agroecosystems favor emergence of new pathogens that can evolve rapidly (McDonald and Stukenbrock 2016) due to homogenous genetic and physical environments. Emerging pathogens are known to cause epidemics and have disastrous consequences on the crops (Burdon et al. 2009). The most important questions regarding an emerging pathogen of a crop are the origin of the pathogen and the risk of that pathogen evolving tolerance to the management practices. Understanding the patterns of genetic variation and evolutionary processes of pathogen populations (Carbone and Kohn 2004) provide means of assessing the evolutionary potential (McDonald and Linde 2002) as well as the population history of a particular fungal pathogen (McDonald 1997). This information can then be utilized in planning effective management strategies.

Colletotrichum tanaceti is an emerging fungal pathogen of the Australian pyrethrum (Tanacetum cinerariifolium) industry. Pyrethrum is a herbaceous perennial plant of the family Asteraceae that is commercially cultivated as a source of the natural insecticides, pyrethrins (Casida and Quistad 1995). Australia accounts for the majority of the world's pyrethrum production (Hay et al. 2015). $C$. tanaceti reduces the available green leaf area and thereby the yield of pyrethrum by producing black, sunken lesions on the foliage that eventually leads to defoliation (Barimani et al. 2013).

${ }^{\dagger}$ Corresponding author: P. W. J. Taylor; paulwjt@unimelb.edu.au

Funding: This project was funded by Botanical Resources Australia-Agricultural Services, Pty. Ltd. The first author received Melbourne International Fee Remission Scholarship and Melbourne International Research Scholarship from the University of Melbourne, Australia.

*The $\boldsymbol{e}$-Xtra logo stands for "electronic extra" and indicates that two supplementary figures and three supplementary tables are published online.

The author(s) declare no conflict of interest.

(C) 2019 The American Phytopathological Society
The disease incidence increases during the Austral winter and decreases during summer. In certain pyrethrum fields, incidence can be as high as 56\% (Hay et al. 2015). Even though C. tanaceti has not been reported from other hosts, a recent study of its genome suggested capacity for a host range greater than just pyrethrum (Lelwala et al. 2019). Pathogenicity genes of $C$. tanaceti are likely to evolve rapidly (Lelwala et al. 2019), increasing the threat imposed by the pathogen to the Australian pyrethrum industry. C. tanaceti is a part of the spring dieback complex of diseases in pyrethrum of Australia and is therefore controlled by up to three fungicide sprays during August to October in all pyrethrum growing regions (Hay et al. 2015; Pethybridge et al. 2008b, 2003). Currently, no fungicides are applied specifically targeting $C$. tanaceti. The disease morphology, taxonomy, asexual disease cycle and the evolution of the genome is well documented for $C$. tanaceti (Barimani et al. 2013; Lelwala et al. 2019). However, the genetic diversity and the structure of populations of $C$. tanaceti in different geographical regions of Australia are unknown.

Sexual reproduction is an important process that increases the evolutionary potential of pathogen populations (McDonald et al. 2016). C. tanaceti has a known heterothallic sexual stage and produces fertile perithecia in vitro (Barimani et al. 2013). However, sexual structures of $C$. tanaceti have not been observed in the field, and there is no knowledge of the extent of sexual reproduction in field populations. Indirect evidence of sexual reproduction can be estimated from population genetic analyses (Dyer and Paoletti 2005) and has been reported in other pathosystems where the teleomorph was not observed (Groenewald et al. 2008; Menat et al. 2016; Pearce et al. 2019). Studying the structure of $C$. tanaceti populations would therefore, enable prediction of the extent of sexual reproduction in the fields and estimation of evolutionary potential of the pathogen.

Gene flow is a major process accelerating adaptive evolution of pathogen populations by introducing new alleles from other populations and counteracting the effect of genetic drift on populations (Carbone and Kohn 2004). Short distance gene flow 
can occur in $C$. tanaceti through splash-dispersal of conidia to neighboring plants. Potential for long-distance dispersal of fungal propagules and anthropogenic transmission of propagules through contaminated seeds, equipment, etc. could inflate the risk by accelerating the allele sharing among distant populations. The two major pyrethrum growing regions in Australia are northern Tasmania and the central west of Victoria, which are separated by a large body of water (Bass Strait). Whether long-distance gene flow occurs between Tasmania and Victoria or among distant populations within a state is unknown.

Understanding the history of pathogen populations and origin of emerging pathogens is important for discovering possible quarantine threats (Barres et al. 2012). The origin of $C$. tanaceti in pyrethrum is unclear. The host plant pyrethrum is native to the Dalmatian coast of Europe (Katsuda 1999) and was introduced to Australia in 1932 (Bhat and Menary 1984). Commercial cultivation of pyrethrum commenced in the 1980s in Tasmania and was later expanded into Victoria in 2008 (Hoyland and van Graver 2010). C. tanaceti was discovered from glasshouse plants in Victoria and field surveys from Tasmania between April and July in 2012 (Barimani et al. 2013). Although it was consistently reported in field surveys since the discovery (Hay et al. 2015), C. tanaceti was not reported in field surveys prior to that (Pethybridge et al. 2003, 2008a). Interestingly, C. tanaceti has only been reported from pyrethrum in Australia and has not been reported from other hosts or from pyrethrum anywhere else. Therefore, whether the pathogen was introduced to Australia or was shifted from another plant that was already present in Australia is unknown.

The following research was conducted to evaluate the evolutionary potential of $C$. tanaceti and the resultant threat to the Australian pyrethrum industry. To achieve this, the aims of this study were to (i) determine the diversity and spatial genetic structure of populations; (ii) infer the reproduction mechanism(s); (iii) infer the potential for long-distance gene flow; and (iv) infer the recent population history of C. tanaceti.

\section{MATERIALS AND METHODS}

Sampling and establishing collections of $C$. tanaceti isolates. $C$. tanaceti isolates $(n=183)$ were obtained from hierarchical sampling of symptomatic leaves from commercial pyrethrum fields along the northern coast of Tasmania and in Victoria during June to July in two consecutive years, 2016 and 2017 (Fig. 1). Another isolate collection $(n=110)$ obtained in 2013 was also included in the analysis. All collections were obtained by intensively searching for leaves displaying symptoms consistent with $C$. tanaceti infection. In 2013, leaves were sampled every $50 \mathrm{~cm}$ along $50 \mathrm{~m}$ transects, which included a field at Melrose, Tasmania $(-41.2530,146.3022)$ and two fields at Table Cape, Tasmania (-40.9487, 145.7088). The 2016 and 2017 collections were obtained by sampling every $50 \mathrm{~cm}$ along two irrigation spray runs across the fields to collect 400 necrotic leaves. The 2016 collection included samples from one field each at Gawler $(-41.2136,146.1544)$ and Kindred, Tasmania (-41.2589, 146.2189), and Bullarook, Victoria $(-37.5295,143.9989)$. In 2017, one field each at Dean, Victoria (-37.4489, 143.9956), Wesley Vale (-41.1851, 146.4435), North Motton (-41.1996, 146.0979), and Penguin, Tasmania $(-41.1167,146.0708)$ was sampled.

From each leaf, one lesion that exhibited anthracnose-like symptoms was selected and a small tissue fragment $\left(\sim 0.5 \mathrm{~mm}^{2}\right)$ was excised from the margin of the lesion. Leaf fragments were surface-sterilized using commercial sodium hypochlorite solution diluted to $0.4 \%$ active chlorine for $1 \mathrm{~min}$, followed by rinsing three times in sterile, double distilled water $\left(\mathrm{ddH}_{2} \mathrm{O}\right)$. After air-drying, five such fragments were placed on a plate of $2 \%$ water agar (WA; Sigma Aldrich, St. Louis) in Petri plates. Plates were incubated at $24^{\circ} \mathrm{C}$ with a $12 \mathrm{~h}$ photoperiod for 5 days. Putative $C$. tanaceti isolates were selected based on previous observations of colony morphology in WA and were subcultured onto potato dextrose agar (PDA; Sigma Aldrich) and incubated at $24^{\circ} \mathrm{C}$ with a $12 \mathrm{~h}$ photoperiod for 5 days. The cultures were then examined under $100 \times$ magnification to confirm $C$. tanaceti colony morphology on PDA and under $400 \times$ to confirm the distinctive spore characteristics (Barimani et al. 2013). A spore suspension $\left(\sim 10^{2}\right.$ spores $\left./ \mathrm{ml}\right)$ of each isolate was prepared, of which $1 \mathrm{ml}$ was poured onto a fresh WA plate and was incubated for $24 \mathrm{~h}$ at $24^{\circ} \mathrm{C}$ to induce germination. Single germinated spores were picked from each plate using a sterile needle, stabbed onto a fresh PDA plate, and incubated to obtain single-spored isolates. Mycelial plugs of $1 \mathrm{~cm}^{2}$ from singlespored cultures on PDA were dried overnight in a biohazard cabinet and stored in sterile cryogenic tubes at $-80^{\circ} \mathrm{C}$ for long-term preservation.

Population assignment and hierarchy. Isolates were collected across 3 years of sampling and nine localities. The term population herein will be used flexibly to refer to either a group of $C$. tanaceti isolates defined by location or collection year. Ten populations were defined based on sampling site: Melrose $(n=38)$, Gawler $(n=27)$, Kindred $(n=28)$, Bullarook $(n=26)$, Dean $(n=26)$, Wesley Vale $(n=28)$, North Motton $(n=22)$, Penguin $(n=25)$, Table Cape1 $(n=44)$, and Table Cape $2(n=28)$, respectively. The two Table Cape populations were from two commercial fields in Table Cape, sampled in 2013. State defined populations included isolates from Tasmania (TAS; $n=241$ ) and Victoria (VIC; $n=52$ ). Furthermore, isolates were also grouped into three populations based on the year they were sampled: $2013(n=110), 2016(n=81)$, and $2017(n=102)$. The two Table Cape pyrethrum crops and the crops from North Motton and Dean were roughly 22 months old and had been exposed to one winter fungicide application and three applications each in spring and summer. All other fields were roughly 10 months old at the time of sampling. Except for Melrose, which received one winter fungicide application, all other 10month-old populations were sampled prior to being exposed to fungicides. The pyrethrum cultivar and the location of the field are further described in Supplementary Table S1.

DNA extraction. Single-spored isolates were grown on PDA for 2 weeks at $24^{\circ} \mathrm{C}$ with a $12 \mathrm{~h}$ photoperiod. Genomic DNA was then extracted from mycelia scraped from the plate surface using the DNeasy Plant Mini Kit (Qiagen, Australia) according to the manufacturer's instructions. DNA was stored at $-20^{\circ} \mathrm{C}$ for longterm storage.

Microsatellite discovery and primer design. The genome assembly of the holotype isolate of $C$. tanaceti (BRIP57314) (Lelwala et al. 2019) was screened for simple sequence repeats (SSR) using the software Tandem Repeat Finder v. 407 (Benson 1999). The search criteria of a minimum score of 50 and matching point of two for all di-to-hexa nucleotide repeats were used. Primer pairs were designed using Primer3 v4.1.0 (Koressaar and Remm 2007; Untergasser et al. 2012) after excluding repeat motifs with $>2$ mismatches and flanking sequences with unknown bases and/or $<50$ base pairs (bp) flanking information available. Primer3 results were limited to amplicon sizes of 150 to $500 \mathrm{bp}$, primers from 18 to $20 \mathrm{bp}$ in length, a maximum 4 poly Ns, primer melting temperatures in the range 50 to $58^{\circ} \mathrm{C}$, and primer GC percentage of 30 to $80 \%$. The sequences containing SSR regions were searched against the nucleotide NCBI nr database using BLAST+ v2.7.1 (Camacho et al. 2009) to confirm they were from noncoding regions. Primers were synthesized (Bioneer-Pacific, Kew East, Australia) and were used to amplify the DNA of the holotype isolate.

Polymerase chain reaction (PCR) was performed in reactions of $12 \mu \mathrm{l}$ of final volume with $1.2 \mathrm{ng}$ of template DNA, $5 \mu \mathrm{l}$ of $10 \times$ Immobuffer (Bioline (Aust) Pty. Ltd., Eveleigh, Australia), $0.96 \mu \mathrm{l}$ of $50 \mathrm{mM} \mathrm{MgCl}$ solution (Bioline), $0.24 \mu \mathrm{l}$ of $100 \mathrm{mM}$ dNTP mix (Bioline), $0.24 \mu$ of Immolase DNA polymerase (Bioline), with $0.2 \mu \mathrm{M}$ of each forward and reverse primer, and the final volume was adjusted by adding $\mathrm{ddH}_{2} \mathrm{O}$. The reactions were 

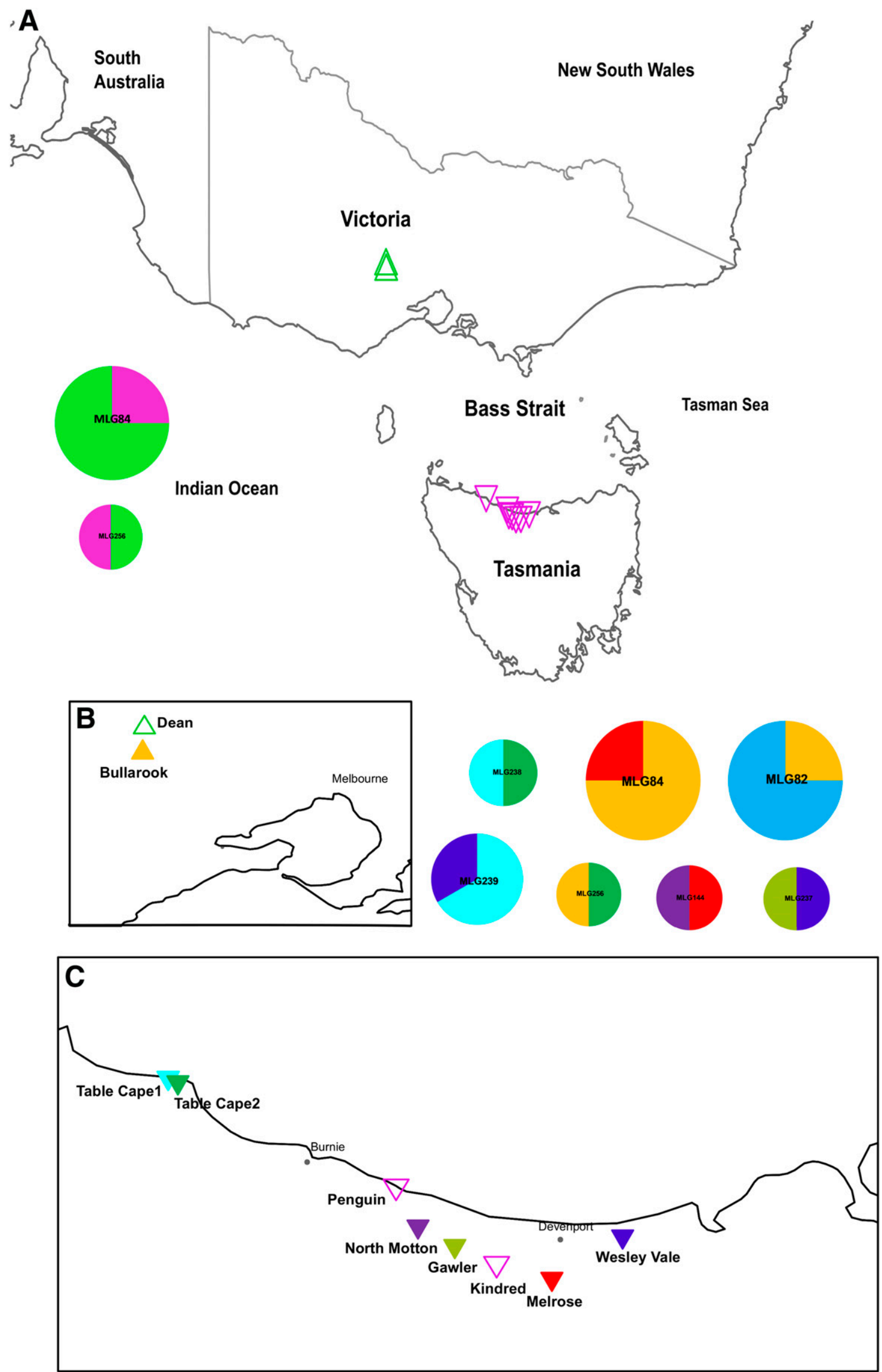

Fig. 1. Distribution of sampling sites and the multilocus genotypes (MLGs) shared across the two states. A, Sampling sites in Victoria (triangles) and in Tasmania (inverted triangles). B, A zoomed view of the distribution of sampling sites in Victoria. C, A zoomed view of the distribution of the sampling sites in Tasmania. The size of the circles (pie charts) corresponds to the total number of clones in the shared MLGs from all populations (large circle indicates four clones, medium circle indicates three clones, and small circle indicates two clones). The colors in the pie charts correspond to the color attributed to the population of their origin in the maps. Each pie chart is generated according to the fraction of the number of clones of a particular MLG that is originating from a population. 
performed in a Bio-Rad thermocycler (Bio-Rad Laboratories Pty. Ltd., NSW, Australia) as follows: 15 min preincubation at $95^{\circ} \mathrm{C}$ followed by 35 cycles of denaturation for $30 \mathrm{~s}$ at $95^{\circ} \mathrm{C}$, annealing at $50^{\circ} \mathrm{C}$ for $30 \mathrm{~s}$, and extending for $30 \mathrm{~s}$ at $72^{\circ} \mathrm{C}$. Reactions concluded with a final extension step of $10 \mathrm{~min}$ at $72^{\circ} \mathrm{C}$. The PCR products were visualized on a $1 \%$ agarose gel and products of primers with a single band were purified using the QIAquick PCR Purification Kit (Qiagen) according to manufacturer's instructions. The purified PCR products were direct sequenced using same PCR primers and the BigDye Terminator chemistry (Thermo Fisher Scientific, Scoresby, Australia) on the Applied Biosystems 3730xl DNA Analyzer (AGRF, Melbourne, Australia) to confirm accurate amplification of the target SSR. A total of 13 loci were chosen for downstream analysis based on intense amplification of a single band after the PCR optimization.

Detection of polymorphism and genotyping error. The forward primers for confirmed SSR loci $(n=13)$ were resynthesized with a $5^{\prime}$ fluorescent label and were tested for polymorphism against $30 \mathrm{C}$. tanaceti isolates selected as representatives from different regions of 2013 collection (Supplementary Table S2). Capillary electrophoresis was conducted (AGRF) in 96-well plates on an ABI 3730 DNA analyzer using GS500 (-250) Liz size standard (Life Technologies Australia Pty. Ltd., VIC, Australia). Allele sizes were determined using Genemapperv.4.1 (Currie-Fraser et al. 2010) (data available on 10.6084/m9.figshare.7000271). Genotyping was replicated three times with independent PCR to calculate the genotyping error and to confirm the reproducibility of the markers. Mean error rate was calculated for each locus (Pompanon et al. 2005). Polymorphic loci with at least two alleles were used for genotyping of the isolate collection ( $n=293)$ after multiplexing using the Multiplex Manager 1.2 (Holleley and Geerts 2009) with a minimum size difference of $50 \mathrm{bp}$ between the loci to be tagged with the same fluorescent dye.

Evaluation of SSR markers. SSR markers were evaluated for their individual informativeness for population genetic analyses using the genotypic data of all 293 isolates, as following. The Ewens-Watterson neutrality test (Manly 1985) was conducted in POPGENE v.1.32 (Yeh FC 2016) with 1,000 simulations to test for departure from selective neutrality of the SSR loci for the overall population. The polymorphic information content (PIC) (Botstein et al. 1980) was also computed for individual markers. A genotype accumulation curve was generated using the package poppr v2.6.0 (Kamvar et al. 2014, 2015) in the R statistical language v3.3.2 (R Core Team 2015) to determine a threshold required to discriminate among unique individuals in a random sample of $n$ loci.

Estimation of gene and genotypic diversity. Allele frequencies were computed for year, state and the field sampled, using GenAlEx v6.5 (Peakall and Smouse 2012). To enable comparison of allelic diversities among populations with unequal sample sizes, allelic richness $\left(R_{a}\right)$, and generalized private allelic richness $\left(R_{p}\right)$ were estimated for each population using rarefaction to account for unequal population sizes, as implemented in ADZE v.1.0 (Szpiech et al. 2008). Nei's unbiased gene diversity $\left(N_{e}\right)(\mathrm{Nei}$ 1973), which is the probability of two randomly drawn alleles from the gene pool being identical at a given locus, was computed for all populations separately in GenAlEx v6.5 (Peakall and Smouse 2012). Multilocus genotypes (MLGs) were defined and analyzed for genotypic diversity using the package poppr. Unique MLGs were first identified based on string comparison, then filtered and collapsed into multilocus lineages (MLLs) based on their genetic distance using the "mlg.filter" function (Kamvar et al. 2015) in poppr. The farthest neighbor algorithm (Kamvar et al. 2015) was applied to Bruvo's distance estimates (Bruvo et al. 2004) to determine a suitable threshold, which is the minimum distance required for two MLGs to be considered unique. All possible thresholds were first recovered and gaps in the distribution of distances/thresholds, which represent clonal groups, were recovered to find the largest threshold difference. The average of that threshold difference was computed using the "cutoff_predictor" function in poppr and was applied using the mlg.filter to collapse the MLGs into MLLs. This MLL assignment method aims to minimize bias caused by somatic mutations, genotyping and allele-calling error in identifying the true clones. A subset of data that was censored for clones (clone-corrected) was generated by retaining only one representative from each MLL.

The following multilocus genotypic diversity indices were computed using poppr for all populations. The MLG richness was computed using the eMLG index, which was approximated based on a rarefaction curve using 1,000 bootstraps (Grünwald et al. 2003) to account for differences in the sample size among populations. Genotypic evenness, which is a measure of the distribution of genotype abundances was measured using the index, E.5 (Ludwig and Reynolds 1988). Genotypic diversity was estimated using Simpson's index $(\lambda)$ (Simpson 1949) through 1,000 jack-knife replicates in rarefaction. MLGs shared across states and populations were identified using poppr.

Reproduction mode. Populations were tested for linkage disequilibrium with the null hypothesis of random association of alleles observed at different loci. Original MLL data were used to compute the standardized index of association $\left(\bar{r}_{d}\right)$ (Agapow and Burt 2001) to test for multilocus linkage disequilibrium with 999 permutations using poppr. The analysis was rerun for clonecorrected data to eliminate masking of recombination by clones. The significance values for the likelihood of observing a recurrent multilocus genotype resulting from sexual reproduction were computed for the original dataset of the two state populations using the software MLGsim2.0 (Ivens et al. 2012; Stenberg et al. 2003). The $P_{\text {sex }}$ which is the likelihood of finding at least as many identical MLGs as observed in a panmictic population (Stenberg et al. 2003) was estimated for each state population. Ten thousand random simulations were conducted in MLGsim2.0 based on the allele frequencies and the sample size of the populations to generate an empirical distribution of $P_{\text {sex }}$ values, against which the observed $P_{\text {sex }}$ value was tested. The resulting $P$ value is an estimate of how statistically significantly low the $P_{\text {sex }}$ is for an individual, and therefore how likely that individual is not a product of sexual reproduction (Ivens et al. 2012).

Population subdivision. The original MLG data with three defined strata (year/state/field) were used to test the null hypothesis of no spatial or temporal differentiation via analysis of molecular variance (AMOVA) (Excoffier et al. 1992) in poppr. The data were divided into two sets where the first comprised data from 2016 and 2017 from both states. The second comprised all three years, but only from Tasmania, since 2013 sample collection lacked data from Victoria. For the first subset, population structure was assessed for the "within states," "among fields within states," and the "within each field" population structural components. For the second subset, population structure was assessed for the "within years," "among fields within year" and the "within each field" population structural components. The genetic variance estimates, and their significance were also computed. Bruvo's distance (Bruvo et al. 2004) was used in the AMOVA to compute variance $(\sigma)$ and percentage variance in poppr. MLGs were filtered within AMOVA with the same parameters used previously for MLG assignment. To test whether populations are significantly different, randomization tests were conducted with 999 random permutations. The analysis was then repeated after clone correcting MLLs for the lowest hierarchical stratification (field). Pairwise $\Phi_{P T}$ values were computed and tested for significance with 999 permutations in GenAlEx v6.5 to test for significant differentiation among pairs of field populations. The probability estimates were adjusted using the Holm correction (Holm 1979) for multiple pairwise comparisons using the $\mathrm{R}$ statistical language v3.3.2. Mantel test for matrix correspondence was performed for the field populations in both states and in Tasmania, separately using GenAlEx v6.5 to test for correlation $\left(R_{x y}>0\right)$ between pairwise genetic distance and 
geographic distance (both log-transformed and linear), matrices according to the isolation-by-distance (IBD) hypothesis.

Discriminant analysis of principal components (DAPC) (Jombart et al. 2010) was executed in the R package adegenet $\mathrm{v} 2.1 .0$ (Jombart 2008) as a model-free approach to further unravel possible complex genetic clusters and to visualize the among population variation. DAPC itself requires that the populations/groups be defined prior to the analysis. Since our data were in two a priori defined strata (year/ state/field), the number of groups that truly exist and are biologically meaningful is the question. Therefore, first the data were clustered using the "find.cluster" function implemented in adegenet, which first transforms the data into principal components and then implements $k$-means clustering of the transformed data. The optimal number of clusters to describe the data were identified as the number with lowest Bayesian Information Criterion (BIC). The inferred clusters were compared with the originally defined populations. The populations from the level of hierarchy that best explains the clustering was used in the actual DAPC analysis. The number of PCs to be retained was determined using the crossvalidation method implemented within adegenet. The collection of PCs with "highest mean success" and lowest "root mean squared error" was retained. A scatterplot and a "compoplot" were generated to visualize the results. The DAPC was then repeated with the clone-corrected dataset.

Population demographic history. Possible pathways for introduction of $C$. tanaceti were compared using Approximate Bayesian Computation (Beaumont et al. 2002) in DIYABC v 2.0 (Cornuet et al. 2014). For this analysis, the existence of two groups of populations, Tasmania and Victoria was assumed. The populations within a state within a year were pooled and populations from the same state sampled in different years were assumed to be samples of the same population, based on the DAPC and AMOVA results. Four possible scenarios of the origin of C. tanaceti were tested (Fig. 2): (i) Victorian population gives rise to Tasmanian population (invasion of Tasmania); (ii) Tasmanian population gives rise to Victorian population (invasion of Victoria); (iii) Tasmania has diverged independently to Victoria from an unsampled ancestral population followed by independent divergence of Victorian population; and (iv) Victorian population diverged independently to Tasmania from an unsampled ancestral population followed by independent divergence of Tasmania. The above scenarios were simulated 4,000,000 times in DIYABC with uniform priors defined. The time priors were defined in number of generations. The sampling time $\mathrm{t} 1$ (2016) was 1 year apart from the present (2017). Since a precise estimation of generation time of $C$. tanaceti is unknown, a wide range of priors were defined for $\mathrm{t}$ ( $\mathrm{t} 1=1$ to $1,000, \mathrm{t} 2=3$ to $3,000, \mathrm{t} 3=3$ to 10,000, Db-duration of botteleneck $=1$ to 1,000 ) with the conditions $\mathrm{t} 2>\mathrm{t} 1$ and $\mathrm{t} 3>\mathrm{t} 2, \mathrm{t} 4>$ $\mathrm{t} 3$. For the demographic parameters, the priors were set as N1 and N2, 10 to 10,$000 ; \mathrm{N} 3,10$ to 100,$000 ; \mathrm{N} 1 \mathrm{~b}$ and N2b, 1 to 1,000 with the conditions N3 $>\mathrm{N} 1, \mathrm{~N} 3>\mathrm{N} 2, \mathrm{~N} 1 \mathrm{~b}<\mathrm{N} 1$ and N2, N2b $<\mathrm{N} 1$ and $\mathrm{N} 2$. The posterior probability of each scenario was computed by direct and logistic regression methods to test for the best scenario. Model check was performed for the scenario with the highest posterior probability but with different test statistics than previously used, to check how well the model fits to the observed data. The type I error was computed for the best scenario by simulating 1,000 datasets according to that scenario and recovering the number of times that it was rejected. The type II error was computed by simulating 1,000 datasets using the other two scenarios and recovering the number of times the correct scenario was chosen.

Gene flow between Victoria and Tasmania. Possible occurrence of gene flow between Tasmania and Victoria was assessed using a coalescence-based isolation with migration model in IMa2 (Hey 2010; Hey and Nielsen 2007) to distinguish between patterns of allele sharing that occurs due to gene flow from those that occur due to ancestral polymorphism. The objective was to test for possible occurrence of long-distance gene flow in $C$. tanaceti (between the states) rather than to compare the extent of gene flow between the years. Therefore, only the 2016 populations were used in the analysis as indicated below. The two populations (Gawler and Kindred) were pooled as the Tasmanian population, and the Bullarook population was used as the population from Victoria. The 2017 populations were not tested due to the distinct genetic composition of the Dean population from Victoria (see Results below), and the asymmetry of the sampling sizes from the two states. The effective population size $(\theta)$, migration rate $(M)$, and the splitting times of the populations $(t)$ were estimated in IMA2 according to the stepwise mutation model (SMM) (Kimura and Ohta 1978). The analyses were performed with uniform priors $(\theta=$ $100, M=100, t=100)$. The Markov Chain Monte Carlo was run three times independently for 3,000,000 million steps, sampling the posterior distribution every 100 steps, with a burn-in of 100,000 steps. Effective sample size values larger than 100 (Kuhner and Smith 2007), the rates of parameter update, and the similarity among runs were considered evidence of convergence of the MCMC search algorithm. The migration parameters and their associated $95 \%$ highest posterior density intervals (HPD95Lo and HPD95Hi) values were used to calculate migration rate per year. The log-likelihood ratio (LLR) statistics were used to test whether the migration rates were greater than zero (Hey and Nielsen 2007). The estimates of population migration rate $(2 \mathrm{NM})$, which is the effective number of gene migrations received by a population per generation was also computed using IMa2 (Hey 2010).

\section{RESULTS}

Evaluation of SSR markers. A total of 135 repeat motifs were detected and 42 primer pairs were designed initially. Thirteen SSR markers were optimized for annealing at $50^{\circ} \mathrm{C}$, of which 11 polymorphic markers were used for genotyping (Table 1). No genotyping error was reported for the eight markers tested. Of the remainder, CT19, CT22, and CT39 each had genotyping errors of 0.0083. The Ewens-Watterson neutrality test indicated no significant deviation of the allele distributions from neutral expectations (Supplementary Table S3). All loci were polymorphic and the genotype accumulation curve (Supplementary Fig. S1) suggested that a plateau had been reached in the number of MLGs for the number of loci used and adding more markers would not significantly increase the MLG resolution. Therefore, 11 loci were considered adequate to discriminate among unique individuals (different MLGs) in a random sample.

Gene diversity. Allelic richness $\left(R_{a}\right)$ averaged across loci within field populations ranged from 2.88 (Wesley Vale) to 4.53 (Gawler) and the private allelic richness $\left(R_{p}\right)$ ranged from 0.06 (Wesley Vale) to 0.82 (North Motton) (Table 2). The Tasmanian population possessed higher allelic richness (6.38) and private allelic richness (5.36) than the Victorian population (5.36 and 1.49, respectively). For field populations it ranged from 0.40 (Wesley Vale) to 0.57 (Gawler). The Tasmanian population had marginally higher gene diversity $\left(N_{e}\right)(0.51)$ than the Victorian population (0.49).

Genotypic diversity. A total of 293 genotyped isolates were assigned to 260 original MLGs based on their allelic makeup. These were then collapsed into 249 distinct MLLs based on a cut-off distance threshold of 0.057 . The genotypic diversity was high $(\lambda=0.981$ to 0.878 ) for populations from all hierarchies. Both the corrected Simpson's $(\lambda=0.955)$ index of genotypic diversity and estimates of evenness $(\mathrm{E} .5=1)$ were highest in Kindred. The lowest genotypic diversity $(\lambda=0.878)$ was reported in Dean (Table 2$)$. The genotypic diversity of Tasmania $(\lambda=0.980)$ was higher than that of Victoria $(\lambda=$ 0.956). Two MLGs were present in both states whereas seven MLLs were shared between at least two field populations (Fig. 1).

Reproduction mode. The test for linkage disequilibrium, using the MLL data and the standardized index of association $\left(\bar{r}_{d}\right)$ resulted in rejection of a null hypothesis of random association of 
A Scenario 1

- N1

- N2

- N2b

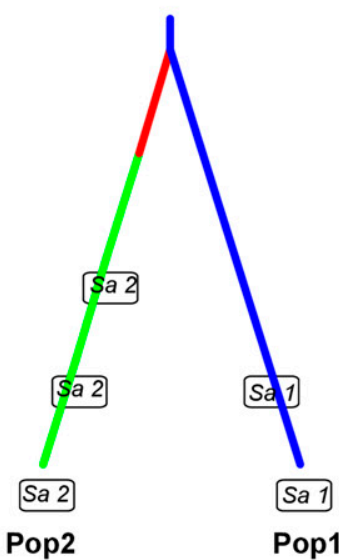

\section{Scenario 3}

- N1b

- N1

- N2

- N3

- N2b

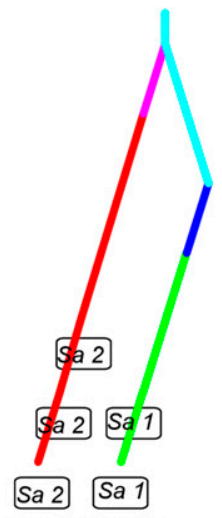

Pop2 Pop1

B

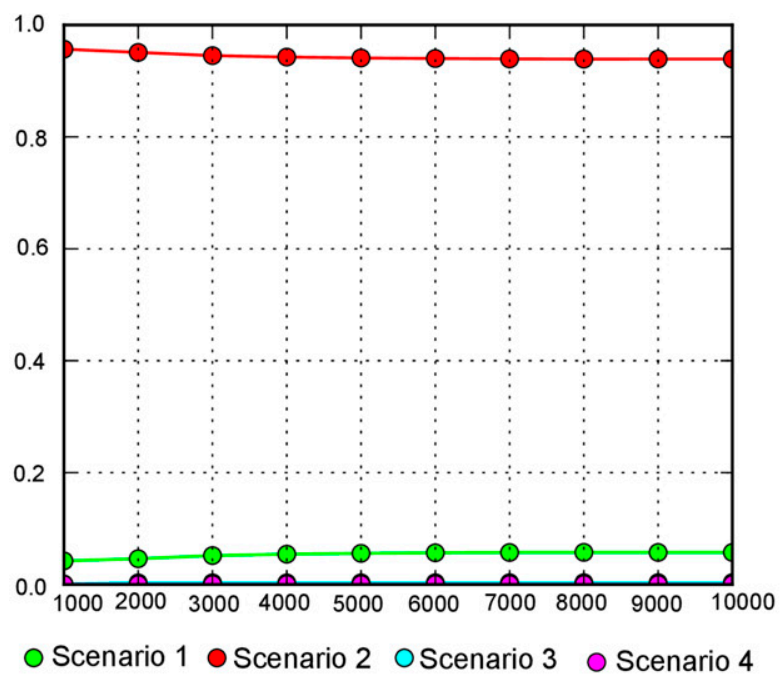

Scenario 2

- N1b

N1

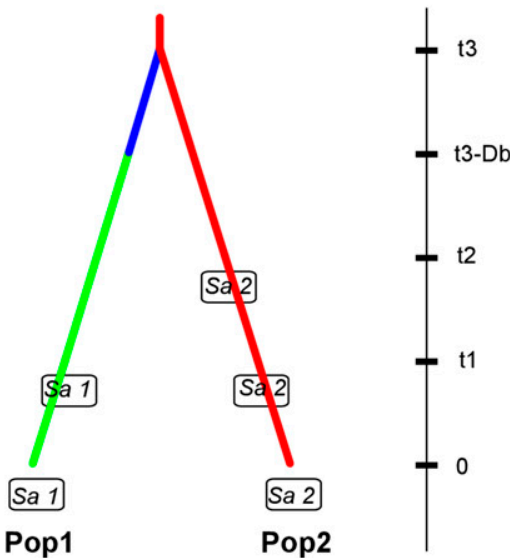

Scenario 4

- N1b

$-\mathrm{N} 1$

N2

- N2b
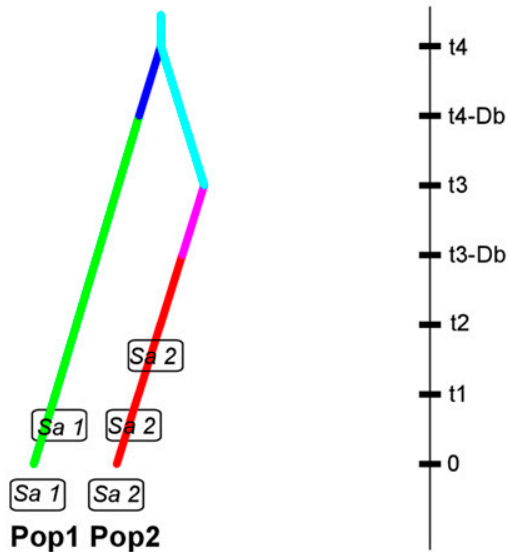

Pop1 Pop2

\section{C}

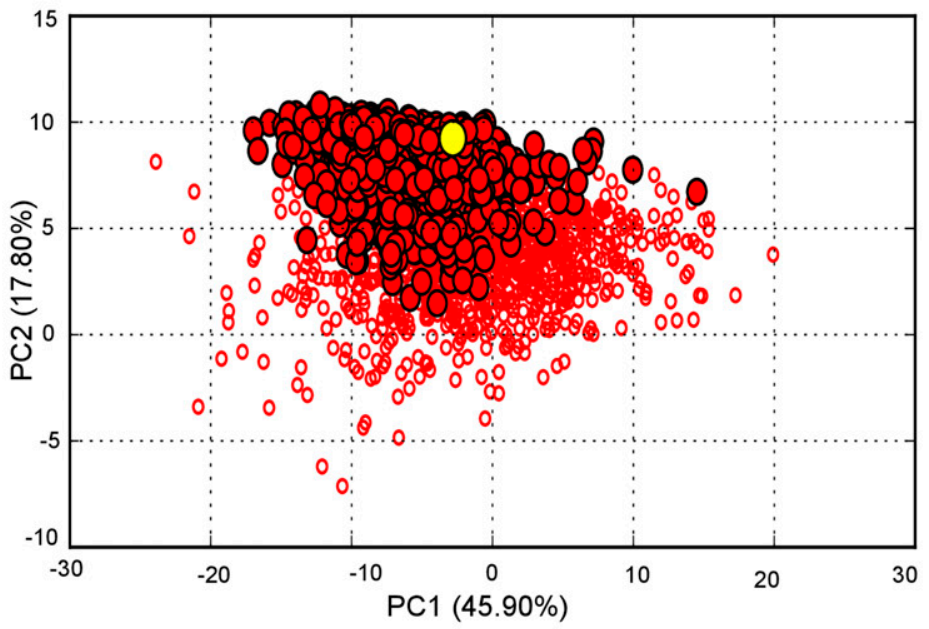

- Scenario 2 prior

O Scenario 2 posterior

$\bigcirc$ Observed data set

Fig. 2. Scenarios explored in and results of DIYABC analyses. A, Four scenarios tested for origin of Colletotrichum tanaceti in pyrethrum; scenario 1, Victorian population (N1) gives rise to Tasmanian population (N2b and N2) (invasion of Tasmania); scenario 2, Tasmanian population (N2) gives rise to Victorian population (N1b and N1) (invasion of Victoria); scenario 3, Tasmania (N2b and N2) is diverged independently to Victoria from an unsampled ancestral population (N3) followed by independent divergence of Victorian population (N1b and N1); and scenario 4, Victorian population (N1b and N1) diverged independently to Tasmania from an unsampled ancestral population (N3) followed by independent divergence of Tasmania (N2b and N2). The above scenarios were simulated 4,000,000 times in DIYABC with uniform priors defined. B, Comparison of posterior probabilities of scenarios using the logistic regression approach. C, The goodness-of-fit test for the observed data for the scenario 2 . 
alleles for four fields: Bullarook $(P=0.001)$, Dean $(P=0.001)$, Gawler $(P=0.044)$, and Penguin $(P=0.004)$ (Table 2$)$. After clonecorrection the null hypothesis could not be rejected $(P=0.188)$ for Penguin and Gawler $(P=0.245)$ populations but significant linkage disequilibrium was still indicated for the Dean $(P=0.046)$ and
Bullarook $(P=0.005)$ populations. For all other field populations, the null hypothesis of random association of alleles could not be rejected for either clone-corrected or uncorrected data $(P \geq 0.142)$. The $\bar{r}_{d}$ values of field populations of $n<25$ did not change significantly when resampled using 50 replicates. In state

TABLE 1. Microsatellite markers selected for genotyping Colletotrichum tanaceti populations

\begin{tabular}{|c|c|c|c|c|c|c|c|c|}
\hline Contig & Primer name & Sequence $\left(5^{\prime}-3^{\prime}\right)$ & Length & $\mathrm{GC}(\%)^{\mathrm{a}}$ & $\mathrm{T}_{\mathrm{m}}^{\mathrm{b}}$ & Expected product size & Repeat unit & $\mathrm{PIC}^{\mathrm{d}}$ \\
\hline \multirow[t]{2}{*}{ FL88-1 } & CT9-F & TGACCACACCATAACAGATG & 20 & 45.00 & 55.15 & \multirow[t]{2}{*}{423} & \multirow[t]{2}{*}{ (TCTG)n } & \multirow[t]{2}{*}{0.095} \\
\hline & CT9-R & GATATGGGAATGATGGTTTG & 20 & 40.00 & 55.18 & & & \\
\hline \multirow[t]{2}{*}{ FL102-1 } & CT10-F & AAAAGGGGTTTAACCTCAAC & 20 & 40.00 & 54.91 & \multirow[t]{2}{*}{442} & \multirow[t]{2}{*}{ (TGT)n } & \multirow[t]{2}{*}{0.242} \\
\hline & CT10-R & ATCCAGATCCATACAAGTGG & 20 & 45.00 & 54.81 & & & \\
\hline \multirow[t]{2}{*}{ FL258-1 } & CT15-F & GCTGTCTTTTGAGGTATTGC & 20 & 45.00 & 55.11 & \multirow[t]{2}{*}{370} & \multirow[t]{2}{*}{ (TTC)n } & \multirow[t]{2}{*}{0.587} \\
\hline & CT15-R & CTCATGGTGTCCTTCTTCAT & 20 & 45.00 & 55.01 & & & \\
\hline \multirow{2}{*}{ FL324-1 } & CT16-F & ATGGGTAATTGAGACTGACG & 20 & 45.00 & 55.07 & \multirow[t]{2}{*}{420} & \multirow[t]{2}{*}{ (AATC)n } & \multirow[t]{2}{*}{0.503} \\
\hline & CT16-R & TGTGAGGTGTTGATTCTTGA & 20 & 40.00 & 54.96 & & & \\
\hline \multirow{2}{*}{ FL428-1 } & CT19-F & GTTTACTTGATGGCGATAGG & 20 & 45.00 & 54.93 & \multirow{2}{*}{414} & \multirow{2}{*}{ (CTT)n } & \multirow[t]{2}{*}{0.450} \\
\hline & CT19-R & ATTGTGTCGAGAGAATGGAG & 20 & 45.00 & 55.19 & & & \\
\hline \multirow[t]{2}{*}{ FL-558 } & CT20-F & GGATTTTGTAGCATTTCTGG & 20 & 40.00 & 54.90 & \multirow[t]{2}{*}{264} & \multirow[t]{2}{*}{ (TCT)n } & \multirow[t]{2}{*}{0.636} \\
\hline & CT20-R & CCGGAGAAGAACTAGCATTA & 20 & 45.00 & 54.82 & & & \\
\hline \multirow[t]{2}{*}{ FL-584 } & CT21-F & ATTACGTGTGGAGGAAACAC & 20 & 45.00 & 54.97 & \multirow[t]{2}{*}{446} & \multirow[t]{2}{*}{$(\mathrm{ACA}) \mathrm{n}$} & \multirow[t]{2}{*}{0.490} \\
\hline & CT21-R & GCGCTTTAGTCTTCTTCTTG & 20 & 45.00 & 54.76 & & & \\
\hline \multirow[t]{2}{*}{ FL-689 } & CT22-F & ATTCACССТCTTCACTTGG & 19 & 47.37 & 55.00 & \multirow[t]{2}{*}{441} & \multirow[t]{2}{*}{ (TCT)n } & \multirow[t]{2}{*}{0.626} \\
\hline & CT22-R & TTTATGCCTCTTGTCCTGTT & 20 & 40.00 & 54.96 & & & \\
\hline \multirow[t]{2}{*}{ FL128-1 } & CT33-F & TGCCACAAAGACAGTAGATG & 20 & 45.00 & 54.75 & 371 & (TCT)n & 0.493 \\
\hline & CT33-R & TGTTAGCTGTCTGGTCATCA & 20 & 45.00 & 55.19 & & & \\
\hline FL90-1 & CT36-F & ACAGACAGACAGGCAGACTT & 20 & 50.00 & 54.88 & 439 & (TTC)n & 0.379 \\
\hline & CT36-R & CCCGTTCTTTAATCTTTGTG & 20 & 40.00 & 54.99 & & & \\
\hline FL140-1 & CT39-F & TACCTAGTGCAGGTGACACA & 20 & 50.00 & 55.14 & 447 & (TGTA)n & 0.618 \\
\hline & CT39-R & ATTTACCAGCTACCCCTTTC & 20 & 45.00 & 55.02 & & & \\
\hline
\end{tabular}

a Guanine and cytosine content of primer.

b Melting temperature.

c Expected product size based on whole genome sequencing of isolate BRIP57314.

d PIC = polymorphic information content.

TABLE 2. Gene and genotypic diversity and linkage disequilibrium indices of Colletotrichum tanaceti populations

\begin{tabular}{|c|c|c|c|c|c|c|c|c|c|c|c|c|c|c|c|}
\hline \multirow[b]{2}{*}{ Population } & \multirow[b]{2}{*}{$N^{\mathrm{a}}$} & \multirow[b]{2}{*}{$n^{\mathrm{b}}$} & \multirow[b]{2}{*}{$N_{a}^{\mathrm{c}}$} & \multirow[b]{2}{*}{$R_{a}^{\mathrm{d}}$} & \multirow[b]{2}{*}{$R_{p}^{\mathrm{e}}$} & \multirow[b]{2}{*}{$N e^{\mathrm{f}}$} & \multirow[b]{2}{*}{$\mathrm{MLG}^{\mathrm{g}}$} & \multirow[b]{2}{*}{$\mathrm{MLL}^{\mathrm{h}}$} & \multirow[b]{2}{*}{$\mathrm{eMLG} \pm \mathrm{SE}^{\mathrm{i}, \mathrm{j}}$} & \multirow[b]{2}{*}{ E. $5^{\mathrm{j}, \mathrm{k}}$} & \multirow[b]{2}{*}{$\lambda^{\mathrm{j}, 1}$} & \multicolumn{2}{|c|}{ Origina $\mathrm{j}^{\mathrm{j}, \mathrm{m}}$} & \multicolumn{2}{|c|}{$\begin{array}{c}\text { Clone- } \\
\text { corrected }^{\mathrm{j}, \mathrm{n}}\end{array}$} \\
\hline & & & & & & & & & & & & $\bar{r}_{d}^{\mathrm{o}}$ & $P^{p}$ & $\bar{r}_{d}{ }^{o}$ & $P^{p}$ \\
\hline Tasmania & 241 & 52 & 11.46 & 6.38 & 5.36 & 0.511 & 222 & 217 & $50.7 \pm 1.08$ & 0.985 & 0.980 & 0.001 & 0.399 & -0.001 & 0.58 \\
\hline Melrose & 38 & 22 & 5.27 & 4.22 & 0.57 & 0.446 & 34 & 33 & $20.2 \pm 1.01$ & 0.956 & 0.946 & -0.003 & 0.584 & -0.011 & 0.765 \\
\hline Table Cape 1 & 44 & 22 & 5.82 & 4.40 & 0.40 & 0.492 & 42 & 42 & $21.5 \pm 0.59$ & 0.989 & 0.953 & 0.000 & 0.501 & -0.007 & 0.724 \\
\hline Table Cape 2 & 28 & 22 & 4.36 & 4.08 & 0.59 & 0.490 & 27 & 27 & $21.4 \pm 0.48$ & 0.985 & 0.952 & 0.010 & 0.239 & 0.007 & 0.319 \\
\hline Gawler & 27 & 22 & 4.82 & 4.53 & 0.71 & 0.569 & 23 & 23 & $19.4 \pm 0.83$ & 0.951 & 0.944 & 0.025 & 0.044 & 0.010 & 0.245 \\
\hline Kindred & 28 & 22 & 4.18 & 3.86 & 0.16 & 0.507 & 28 & 28 & $22.0 \pm 0.23$ & 1.000 & 0.955 & 0.013 & 0.142 & 0.013 & 0.132 \\
\hline Wesley Vale & 29 & 22 & 3.09 & 2.88 & 0.06 & 0.404 & 27 & 26 & $20.3 \pm 0.80$ & 0.964 & 0.948 & 0.008 & 0.258 & -0.002 & 0.522 \\
\hline North Motton & 22 & 22 & 4.46 & 4.45 & 0.82 & 0.506 & 21 & 21 & $21.0 \pm 0.00$ & 0.975 & 0.950 & 0.002 & 0.421 & -0.009 & 0.702 \\
\hline Penguin & 25 & 22 & 4.18 & 4.01 & 0.57 & 0.531 & 22 & 21 & $18.7 \pm 0.69$ & 0.860 & 0.932 & 0.048 & 0.004 & 0.011 & 0.188 \\
\hline Victoria & 52 & 52 & 5.36 & 5.36 & 1.49 & 0.489 & 39 & 34 & $34.0 \pm 0.00$ & 0.790 & 0.956 & 0.067 & 0.001 & 0.037 & 0.003 \\
\hline Bullarook & 26 & 22 & 3.91 & 3.68 & 0.31 & 0.438 & 23 & 22 & $19.0 \pm 0.79$ & 0.922 & 0.940 & 0.081 & 0.001 & 0.057 & 0.005 \\
\hline Dean & 26 & 22 & 3.46 & 3.29 & 0.39 & 0.443 & 16 & 13 & $11.9 \pm 0.83$ & 0.817 & 0.878 & 0.114 & 0.001 & 0.038 & 0.046 \\
\hline 2013 & 110 & 81 & 8.55 & 7.58 & 2.16 & 0.483 & 103 & 101 & $76.0 \pm 1.41$ & 0.964 & 0.986 & & & & \\
\hline 2016 & 81 & 81 & 6.82 & 6.82 & 1.41 & 0.528 & 74 & 73 & $73.0 \pm 0.00$ & 0.944 & 0.985 & & & & \\
\hline 2017 & 102 & 81 & 7.00 & 6.45 & 1.82 & 0.500 & 86 & 81 & $66.5 \pm 1.81$ & 0.854 & 0.981 & & & & \\
\hline Total & 293 & & & & & & 260 & 249 & & & & & & & \\
\hline
\end{tabular}

a Number of individuals.

${ }^{b}$ The number of individuals used in rarefaction in ${ }^{\mathrm{d}}$, ${ }^{\mathrm{e}}$, and ${ }^{\mathrm{i}}$ and the number of samples drawn at each replicate of bootstrapping ${ }^{\mathrm{k}}$ and ${ }^{\mathrm{l}}$ (this is the common maximum sample size among populations from the same hierarchical level $(n=22$ for field populations, $n=52$ for state populations, and $n=81$ for year populations).

c Number of alleles averaged across all loci.

d Allelic richness computed using rarefaction implemented in ADZE v 1.0 (Szpiech et al. 2008).

e Private allelic richness computed using rarefaction implemented in ADZE v 1.0 (Szpiech et al. 2008).

f Nei's unbiased genetic diversity computed in GenAlEx v 6.5 (Peakall and Smouse 2012).

g Original number of multilocus genotypes (MLGs).

${ }^{\mathrm{h}}$ Number of multilocus lineages (MLL) after collapsing MLGs, computed using poppr v.2.6 (Kamvar et al. 2014, 2015) package in R (R Core Team 2015).

i Expected number of MLGs \pm standard error after rarefaction for sample size.

$\mathrm{j}$ Indices that were computed using MLL data.

${ }^{k}$ Genotypic evenness; computed with bootstrapping and confidence intervals not shown.

${ }^{1} \lambda$, Simpson's index of genotypic diversity (Simpson 1949), computed with bootstrapping and confidence intervals not shown.

${ }^{\mathrm{m}}$ Computed using the full MLL dataset.

${ }^{n}$ Computed using the clone-corrected dataset which included one member of each MLL for each field population.

o Standardized index of association (Agapow and Burt 2001).

p Probability value of $\bar{r}_{d}$ estimated using one sided permutation test based on 999 samples. 
populations, the Victorian population was in linkage disequilibrium for both original $(P=0.001)$ and clone-corrected $(P=0.003)$ datasets. Ten of the twenty recurrent MLGs in the Tasmanian population and three of the nine recurrent MLGs had $P_{\text {sex }}$ values that were significantly low, suggesting the individuals represented by those MLGs ( $n=23$ in Tasmania and $n=12$ in Victoria) were not all the product of recombination (Table 3). The rest of the recurrent MLGs that had significantly high $P_{\text {sex }}$ values ranging from 0.001 to 0.199 indicate that all members of these MLGs could be the result of sexual reproduction.

Population subdivision. According to AMOVA estimates, most of the genetic variation occurred within the fields for both datasets (Table 4), without (92.77 and $95.57 \%$ variance for the 2016-17 and the Tasmania datasets, respectively) and with clonecorrection (92.96 and $96.44 \%$ variance, respectively). Less, but significant variation was observed among field populations within the two states for 2016-17 dataset (5.78 and $4.44 \%$ of variance without and with clone-correction, respectively) and among fields within years for the Tasmanian population dataset from all 3 years (3.30 and $2.63 \%$ variance without and with clone-correction, respectively) (Table 4). Testing for significance on 9,999 permutations (Table 5) indicated that difference among fields is significant $(P \leq 0.001)$ for both datasets even after clone-correction. There was no significant difference among the years for Tasmanian populations before or after clone-correction $(P \geq 0.09)$. The populations from the two states were not significantly differentiated either before or after clone-correction $(P \geq 0.169)$.

The Mantel test for isolation by distance revealed that there is no significant correlation between the genetic and geographic matrices for both datasets and when both log and linear geographic distances were used $\left(R_{x y}=-0.340, P=0.201\right.$ all populations and $R_{x y}=-0.340$, $P=0.104$ for Tasmanian populations when the linear geographic

TABLE 3. Probabilities of recurrent multilocus genotypes (MLGs) being found in a random mating population

\begin{tabular}{|c|c|c|c|c|}
\hline Population & MLG ID $^{\mathrm{a}}$ & $N^{\mathrm{b}}$ & $P_{\text {Sex }}{ }^{\mathrm{c}}$ & Significance $^{\mathrm{d}}$ \\
\hline \multirow[t]{20}{*}{ Tasmania } & MLG7 & 2 & $<0.001$ & $\leq 0.500$ \\
\hline & MLG16 & 2 & $<0.001$ & 0.331 \\
\hline & MLG35 & 2 & 0.023 & 0.071 \\
\hline & MLG67 & 2 & 0.006 & 0.194 \\
\hline & MLG68 & 2 & 0.006 & 0.183 \\
\hline & MLG74 & 2 & 0.004 & 0.694 \\
\hline & MLG86 & 3 & $<0.001$ & 0.296 \\
\hline & MLG94 & 2 & $<0.001$ & 0.130 \\
\hline & MLG109 & 2 & $<0.001$ & 0.087 \\
\hline & MLG110 & 2 & 0.056 & $\leq 0.001$ \\
\hline & MLG111 & 2 & 0.017 & 0.043 \\
\hline & MLG112 & 3 & 0.199 & 0.442 \\
\hline & MLG134 & 2 & 0.003 & 0.621 \\
\hline & MLG138 & 2 & 0.001 & $\leq 0.500$ \\
\hline & MLG150 & 4 & $<0.001$ & $\leq 0.001$ \\
\hline & MLG170 & 2 & 0.001 & 0.151 \\
\hline & MLG171 & 2 & $<0.001$ & $\leq 0.500$ \\
\hline & MLG172 & 2 & $<0.001$ & $\leq 0.010$ \\
\hline & MLG191 & 2 & $<0.001$ & 0.377 \\
\hline & MLG198 & 2 & $<0.001$ & 0.207 \\
\hline \multirow[t]{9}{*}{ Victoria } & MLG4 & 7 & $<0.001$ & $\leq 0.001$ \\
\hline & MLG11 & 3 & 0.001 & 0.088 \\
\hline & MLG13 & 4 & 0.001 & 0.447 \\
\hline & MLG14 & 3 & 0.001 & 0.247 \\
\hline & MLG17 & 2 & 0.017 & $\leq 0.500$ \\
\hline & MLG18 & 3 & $<0.001$ & $\leq 0.500$ \\
\hline & MLG20 & 2 & 0.004 & 0.331 \\
\hline & MLG23 & 2 & $<0.001$ & 0.071 \\
\hline & MLG28 & 2 & 0.001 & 0.194 \\
\hline
\end{tabular}

a ID of the recurrent MLG.

b Number of times the recurrent MLG is reported in the population.

c Likelihood of sampling each MLG, at least as many times as observed in a panmictic population.

d Critical probability values for testing the significance for the $P_{\text {sex }}$ value estimated by 10,000 random simulations, computed in MLGsim 2.0 (Ivens et al. 2012; Stenberg et al. 2003). distances were used and $R_{x y}=0.054, P=0.31$ for all populations and $R_{x y}=-0.045, P=0.390$ for Tasmanian populations when long geographic distances were used).

Ten genetic clusters were the optimal number according to $k$ means clustering to describe the data based on the lowest BIC value (Supplementary Fig. S2). Nine clusters were not restricted geographically (state/field sampled) or temporally (year sampled). Inferred cluster2 was composed of six clones and another individual of a different MLL, all from the Dean population. The number and composition of inferred clusters coincided with the "field" populations most out of the three predefined strata, but the inferred clusters themselves were not biologically meaningful. Therefore, the 10 predefined "field" populations were used as clusters in the DAPC analysis. A total of 80 PCs were retained after the crossvalidation during the DAPC. The first PC separated Dean from the rest with a slight overlap with the Wesley Vale cluster (Fig. 3), whereas the second PC separated Gawler from all others. The proportion of successful reassignment of individuals to their original clusters based on the discriminant functions was highest for Dean (0.962) followed by Gawler (0.852) but was low for other populations. A total of 50 individuals were reported to have $\geq 95 \%$ membership probability for any cluster which included 23 individuals from Gawler, 20 from Dean, and eight from Wesley Vale. All other individuals, comprising $82.93 \%$ of the total collection, had low membership probabilities to their cluster (Fig. 4). This clustering pattern of DAPC did not change after clonecorrection.

The pairwise $\Phi_{P T}$ values of the field populations showed that the Dean population was distinct from all other populations (Table 5). Additionally, the Gawler population was distinct from all other field populations except Penguin. Both Wesley Vale and Melrose were distinct from all other populations except Table Cape 2 and North Motton.

Demographic history of $\boldsymbol{C}$. tanaceti. The results from DIYABC indicated that the best scenario explaining the history of C. tanaceti is scenario 2, which is invasion of Victoria by the Tasmanian population (Fig. 2B). The second-best scenario is invasion of Tasmania by Victorian populations. These scenarios had a higher probability than the other two scenarios of independent introductions from an unsampled population. The type 1 error for scenario 2 (probability that scenario 2 was rejected even though it is the true scenario) was 0.2 and the type II error (probability of accepting scenario 2 when it is not the true scenario) was 0.06 . The goodness-of-fit test showed datasets simulated with scenario 2 closely matches the observed data (Fig. 2C). According to the parameters, Victoria was colonized by reasonably large number of individuals $(n=1,280)$ roughly around the same time as the first report of the pathogen $(\mathrm{t} 2 \sim=\mathrm{t} 3)$ (Table 6$)$.

Gene flow between Victoria and Tasmania. The marginal posterior probability distributions of migration rate parameters showed clear peaks and were within the prior distribution of the IMa2 analysis. Significant bidirectional migration was observed between the two state populations; from Victoria to Tasmania (LLR test $\geq 3.739, P \leq 0.05$ ) and from Tasmania to Victoria (LLR test $\geq$ $931.568, P \leq 0.001)$. The probability that the migration rate from Tasmania to Victoria was greater than the migration rate from Victoria to Tasmania in 2016 was 0.99 . Population migration rates were also significantly different from zero (LLR test $2 \mathrm{NM} \geq 6.002$, $P \leq 0.05$ for migration from Victoria to Tasmania and $2 \mathrm{NM}=$ $867.892, P \leq 0.001$ for migration from Tasmania to Victoria). The highest probability density range for population migration from Tasmania to Victoria was 2.406 to 63.43. The same for population migration from Victoria to Tasmania was 0.1762 to 1.339 .

\section{DISCUSSION}

The patterns of genetic variation and evolutionary processes of C. tanaceti populations of Australian pyrethrum fields were 
analyzed using a library of neutral polymorphic markers to infer the origin and the evolutionary potential of the pathogen. Populations were little differentiated and $C$. tanaceti was indicated to have a mixed reproductive lifecycle with frequent sexual recombination. Potential for long-distance gene flow in $C$. tanaceti was indicative and results further suggested that Tasmania was the origin of this pathogen.

The high genotypic evenness and diversity values of all $C$. tanaceti populations suggested they had many equally abundant genotypes, an indication of outbreeding sexual reproduction (Dyer and Paoletti 2005; Taylor et al. 1999). Populations were not dominated by one or a few genotypes as would be expected in a typical, predominantly clonal population (Milgroom 1996). The high $P_{\text {sex }}$ estimates for recurrent MLGs suggested that even the individuals in clonal lineages were not necessarily a product of asexual reproduction (Stenberg et al. 2003). The frequent nature of sexual reproduction of $C$. tanaceti was further evident, when evaluated for linkage disequilibrium. The null hypothesis of random association of alleles could not be rejected for majority of the Tasmanian populations suggesting regular recombination and clones had a lesser contribution to the structure of these populations (Burt et al. 1996). If the lack of linkage disequilibrium is an artifact of large size of fungal populations, sampling of few individuals should have resulted linkage disequilibrium (Slatkin 2008). Sexual reproduction is a major source of recombination in fungi (Carbone and Kohn 2004). C. tanaceti has a known sexual stage thus the recombining genetic structure as observed in the analysis of linkage of loci in $C$. tanaceti was likely to be a by-product of recurrent sexual reproduction in the field. Parasexuality has been demonstrated in other Colletotrichum spp. (Alahakoon et al. 1992) and could be a mechanism for recombination (Correll and Gordon 1999). However, C. tanaceti has not been studied for parasexuality and its possible role in generating diversity remains unknown. Furthermore, population subdivision according to AMOVA, DAPC did not change significantly after clone-correction. This further suggested that clonal reproduction was not overly influencing the structure of populations (McDonald 1997). Even though perithecia of $C$. tanaceti have never been observed in field surveys, it is quite possible that sexual structures were missed during the sampling due to either sampling the wrong part of the plant or at the wrong time period. Another possibility is that the sexual stage occurred on another, unidentified host. An alternative host hypothesis agrees with the previous study on the genomics of $C$. tanaceti, which suggested that $C$. tanaceti was likely to have a broader host range than just pyrethrum (Lelwala et al. 2019). Evaluation of the environmental conditions favorable for sexual reproduction in $C$. tanaceti is the subject of ongoing investigation. In typical heterothallic pezizomycotina members, successful sexual reproduction occurs only between isolates of the two opposite mating type specificities, which are dictated by specific genomic regions called "idiomorphs" (Metzenberg and Glass 1990). Therefore, in typical heterothallic mating systems, sexual reproduction occurs only in populations with both idiomorphs (Debuchy and Turgeon 2006). However, in all Colletotrichum spp. tested up to date, both isolates of a successful cross have the same idiomorph (Menat et al. 2012; Rodriguez-Guerra et al. 2005; Vaillancourt et al. 2000).

TABLE 4. Analysis of molecular variance (AMOVA) for the original multilocus lineage (MLL) data and clone-corrected data of Colletotrichum tanaceti field populations

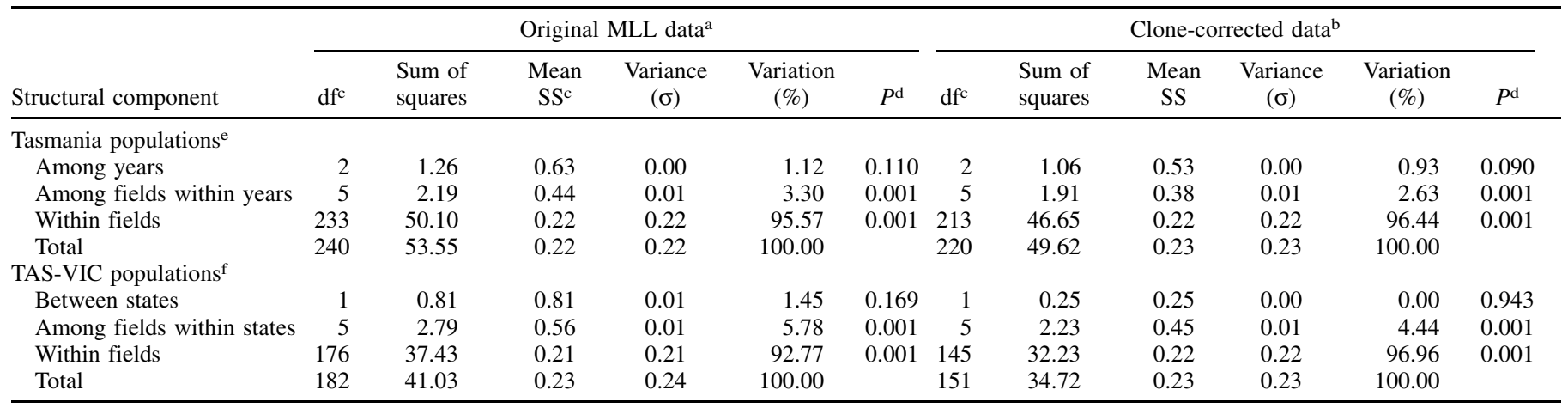

a Original dataset containing all individuals in each population.

b Clone-corrected dataset included one member of each MLL for each field population.

c Degrees of freedom.

${ }^{d}$ Probability of variation percentage being significantly greater than zero.

e Hierarchical AMOVA, partitioning total genetic variance of Tasmanian isolates over 3 years into the following components: among the 3 years (2013, 2016, and 2017), among the field populations in each sampling year, and within the fields sampled.

${ }^{f}$ Hierarchical AMOVA, partitioning total genetic variance of isolates over 2 years into the following components: among the two states (Tasmania [TAS] and Victoria [VIC]), among the field populations in each state and within the fields sampled.

TABLE 5. Pairwise $\Phi_{P T}$ estimates of field populations ${ }^{\mathrm{a}}$

\begin{tabular}{lcccccccccc}
\hline Field populations & Melrose & Table Cape1 & Table Cape2 & Gawler & Kindred & Bullarook & Dean & Wesley Vale & North Motton & Penguin \\
\hline Melrose & & 0.029 & 0.032 & 0.115 & 0.069 & 0.056 & 0.124 & 0.088 & 0.041 \\
Table Cape1 & 0.045 & & 0.005 & 0.081 & 0.027 & 0.031 & 0.104 & 0.058 & 0.018 \\
Table Cape2 & 0.068 & 0.768 & & 0.063 & 0.021 & 0.043 & 0.117 & 0.043 & 0.063 \\
Gawler & 0.045 & 0.045 & 0.045 & & 0.070 & 0.099 & 0.110 & 0.089 & 0.072 \\
Kindred & 0.045 & 0.068 & 0.416 & 0.045 & & 0.004 & 0.106 & 0.058 & 0.017 & 0.046 \\
Bullarook & 0.045 & 0.096 & 0.060 & 0.045 & 0.768 & & 0.107 & 0.071 & 0.033 \\
Dean & 0.045 & 0.045 & 0.045 & 0.045 & 0.045 & 0.045 & & 0.097 & 0.127 \\
Wesley Vale & 0.045 & 0.045 & 0.068 & 0.045 & 0.045 & 0.045 & 0.045 & 0.109 & 0.047 \\
North Motton & 0.060 & 0.416 & 0.768 & 0.045 & 0.498 & 0.187 & 0.045 & 0.078 & 0.059 \\
Penguin & 0.045 & 0.060 & 0.565 & 0.068 & 0.190 & 0.190 & 0.045 & 0.045 & 0.624 & 0.015 \\
\hline
\end{tabular}

a Above diagonal: $\Phi_{P T}$ estimates. Below diagonal: adjusted probability estimates. Estimates adjusted using the Holm correction (Holm 1979) for multiple pairwise comparisons. Corrections undertaken using R (R Core Team 2015). 
Further investigation is needed in the genetics of mating in Colletotrichum and research is ongoing to untangle the apparently complex sexual reproduction strategy of $C$. tanaceti. The genome of $C$. tanaceti published by Lelwala et al. (2019) is a good resource for identifying the mating strategy in field populations.

The observation of clonal lineages within populations was indication of partial clonality in $C$. tanaceti. The two field populations from Victoria, Dean, and Bullarook as well as the pooled population from Victoria departed significantly from linkage equilibrium even after clone-correction. Substantial linkage disequilibrium is expected in populations that are either strictly clonal or do not undergo frequent recombination (de Meeûs and Balloux 2004). The Victorian population is unlikely to be strictly clonal due to the presence of large numbers of MLLs. Also, the contribution of asexual reproduction in creating the observed linkage disequilibrium should be insignificant since the result did not change after censoring the clones (Brown 1999). Significant disequilibrium in the pooled Victorian population could be an artifact of the subpopulation structure (Slatkin 2008). A possible explanation could be that sexual reproduction in Victoria was relatively less prevalent than in Tasmania due to low density of the cultivated host in Victoria. Alternatively, if the sexual stage was on another host, then this host may have limited distribution in Victoria, preventing the Victorian population from undergoing sufficient sexual cycles to eliminate disequilibrium caused by clonal reproduction (Ardlie et al. 2002). Significant linkage disequilibrium even after clone correction has been reported previously in other ascomycetes with a mixed mode of reproduction (Bogacki et al. 2010; Brewer et al. 2012; Brown and Wolfe 1990). In two further fields, Gawler and Penguin, linkage disequilibrium was

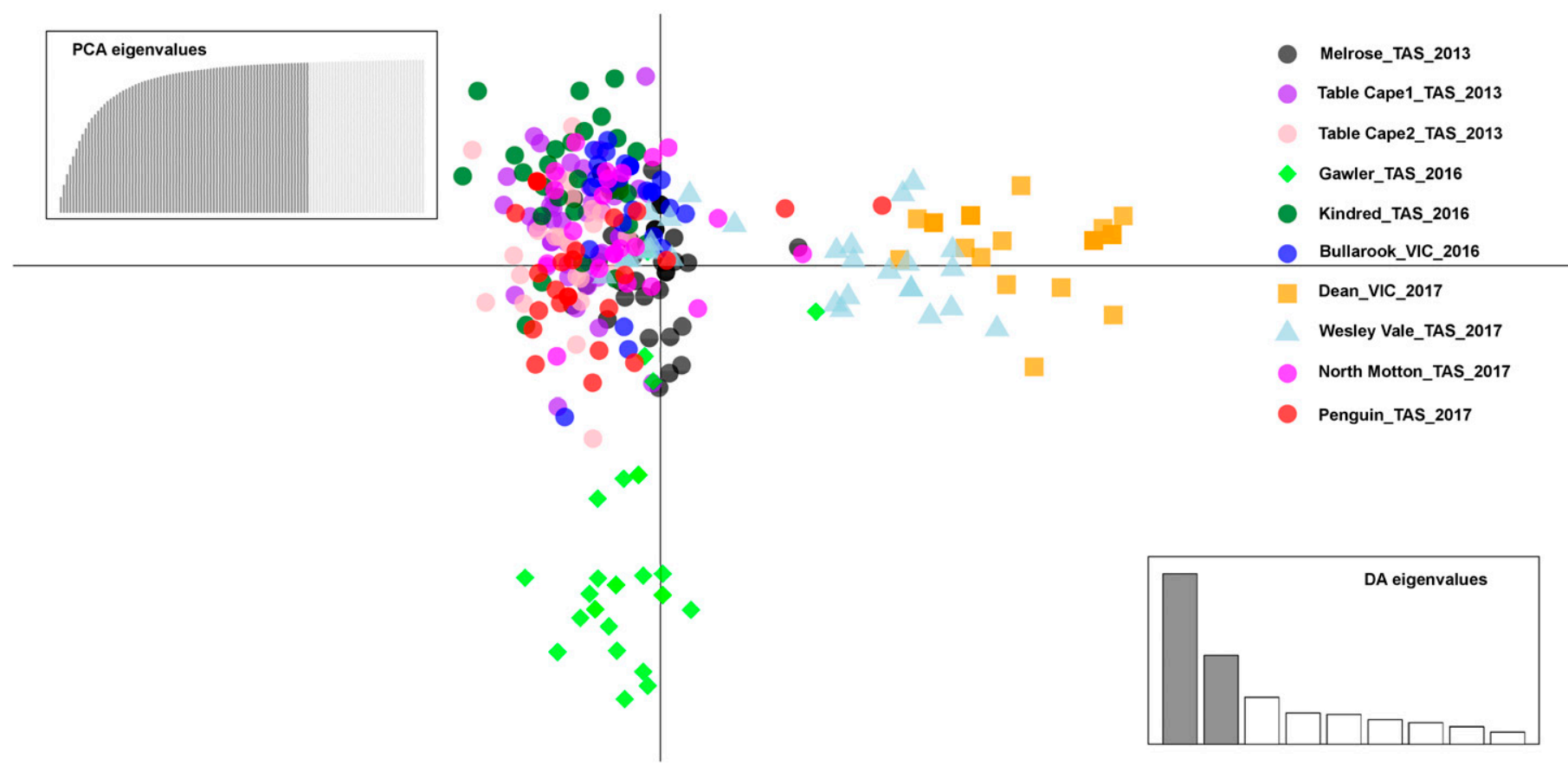

Fig. 3. Scatter plot for the discriminant analysis of principal components of the field populations.

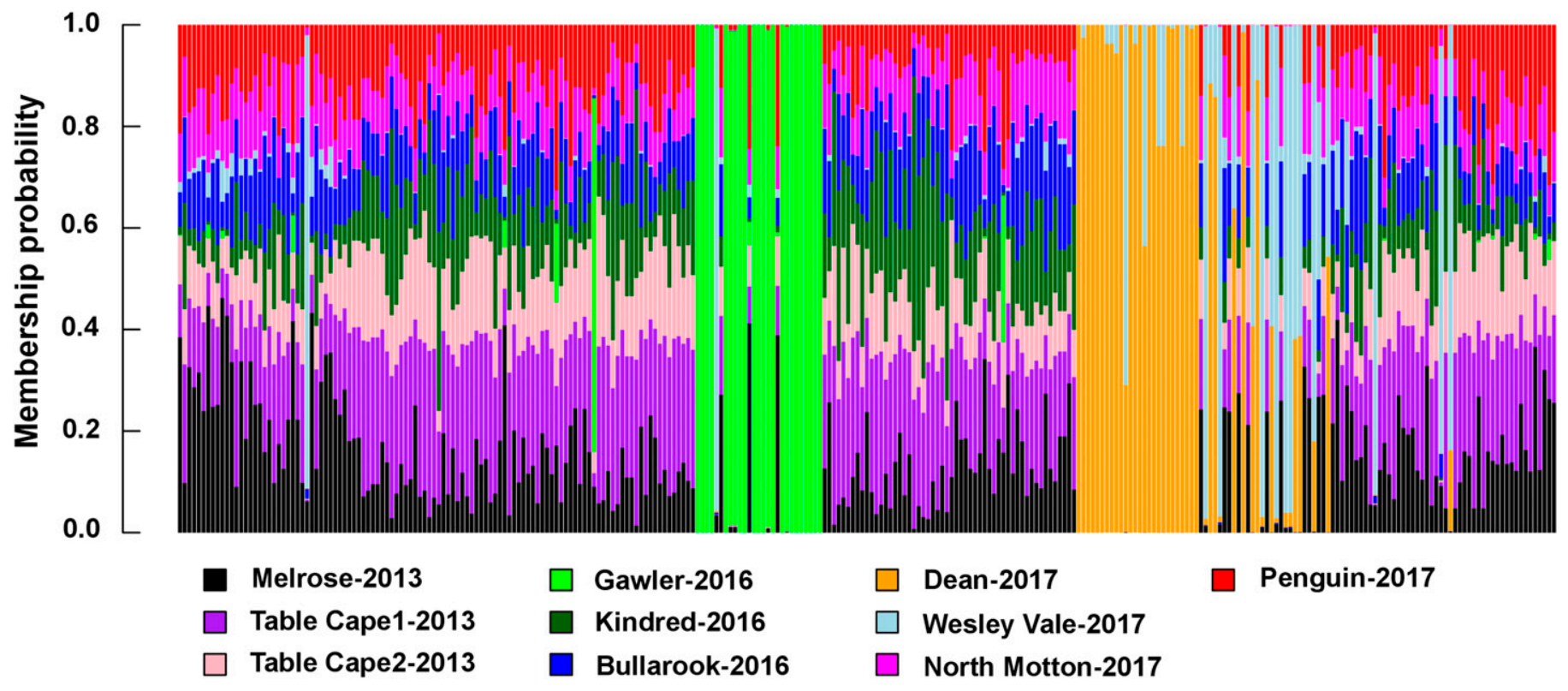

Fig. 4. Compoplot of the discriminant analysis of principal components showing the membership probabilities of the individuals to each of the field clusters. 
detected prior to, but not after clone correction. This was in accordance with the epidemic model of population structure (Smith et al. 1993), where sexual reproduction occurs, but one or a few successful individuals are selected and increase in frequency via clonal reproduction (Brown 1994, 1995). The conservation of some clones across years could be due to a selective advantage of that clone. Generation of the same genotype due to inbreeding is an alternative hypothesis, although considered unlikely due to the high genotypic diversity observed in populations. Taken together, these results suggested $C$. tanaceti had a mixed mode of reproduction, but with frequent sexual reproduction under field conditions. Future studies with populations in different seasons/periods of the same year can be used to test this hypothesis.

Little differentiation was observed among the populations of C. tanaceti. Most genetic variation existed within populations not among populations. Field populations were weakly but significantly differentiated, but there was no evidence to support that this was due to isolation by distance (Wright 1943). The DAPC and the pairwise $\Phi_{P T}$ estimates indicated that differentiation was mainly due to the Dean, Gawler, and Wesley Vale populations being genetically distinct from other populations. The remaining predefined field populations were largely overlapping, and the low membership probability of these populations was suggestive of genetic admixture of populations (Jombart et al. 2010). Even though Dean was the only Victorian population sampled in 2017, the extent of differentiation from Bullarook sampled in 2016 was unlikely to be solely a temporal effect since sampling times were only a year apart. However, this could not be tested vigorously since more populations from Victoria are required from each sampling year. The differentiation of Gawler and Wesley Vale from other Tasmanian populations that were sampled in the same year cannot be explained by its spatial origin or any geographical/temporal barrier to gene flow. The differences in the age and cultivar of the crop, the fungicide treatments received by the crop, the type of soil, or the coastal versus inland location of the crop could also not explain the differentiation of these populations. The fields sampled were within the same geographic regions with temperate cool climatic conditions and same cultural and management practices are conducted in all pyrethrum growing regions of Australia. Therefore, the limitations in the gene flow caused by adaptation to the local environment or the process of isolation by adaptation (Orsini et al. 2013a) to cause these genetically distinct field populations is unlikely. Since the differentiation observed among field populations does not correlate with geographic or ecological factors, the most likely explanation is different introductions followed by isolation by colonization (Orsini et al. 2013b; Spurgin et al. 2014). Under this scenario the initial colonists or the resident individuals of these distinct populations may have priority over any immigrant individuals, thereby obstructing homogenization.

Potential for long-distance gene and genotypic flow was indicated for $C$. tanaceti. Neither AMOVA nor DAPC supported the hypothesis that the two populations from Tasmania and Victoria would be differentiated due to the presence of the large geographical barrier, Bass Strait, which would restrict gene flow. Homogeneity among populations is usually caused by high rates of gene flow (Marko and Hart 2011). Even within Tasmania, certain populations were significantly geographically distant from each other (e.g., Melrose and Table Cape were separated by a linear distance of $\sim 80 \mathrm{~km}$ ). However, those populations were not significantly differentiated, and no correlation was detected between the geographic and genetic distances indicating possible long-distance gene flow, which might have counteracted the effect of isolation by distance (Peterson and Denno 1998). The IMa2 analysis, with a nonzero migration rate between populations from the two states further supported the hypothesis of long-distance gene flow in $C$. tanaceti. Presence of certain multilocus lineages in both states or in different distant fields also provided evidence of possible long-distance genotype flow (McDonald and Linde 2002).

Several possible mechanisms of long-distance gene flow in C. tanaceti exist. The shortest linear distance between Devonport, Tasmania to Ballarat, Victoria is roughly $450 \mathrm{~km}$. Therefore, the gene flow between the two states was unlikely to be due to rain splash dispersal of asexual spore. On the other hand, ascospores are wind-dispersed and may have been able to travel very long distances, even intercontinentally (Rogers and Rogers 1999) in certain fungal genera such as Mycosphaerella (Linde et al. 2002). Ascospores of $C$. gloeosporioides were reported to have been dispersed long distances (>250 m) (Sutton and Shane 1983). However, the viability of ascospores after crossing a large geographical barrier is questionable (Golan and Pringle 2017). Also, wind dispersal of ascospores does not explain the reason for geographically distant populations (populations from two states) to become more genetically similar to each other than populations that are situated closer to each other (population from the same state). Even if ascospores are a possible means of long-distance gene flow in $C$. tanaceti, there would be an expectation of patterns of isolation by distance (Golan and Pringle 2017). Another possible means of pathogen gene flow is anthropogenically (on shoes, farm equipment, seeds, etc.). Anthropogenic transmission could have resulted in gene flow among fields within states since farm equipment are shared between growers. However, equipment was unlikely to have been shared between the two states. Infected pyrethrum seeds have been suggested as a means of gene flow for another pathogen of pyrethrum in Australia, Stagonosporopsis tanaceti (Bhuiyan et al. 2019; Vaghefi et al. 2014). C. tanaceti has also been reported to infect commercial seed stocks at very low levels (Scott et al. 2017). The higher rate of migration from Tasmania to Victoria in 2016 indicated by IMa2 analysis supports both, the anthropogenic transmission of infected seeds, since all pyrethrum seed for sowing is produced in Tasmania and also the wind dispersal of ascospores, since sexual reproduction is likely to be more frequent in Tasmania. Therefore, both mechanisms can be neither disregarded nor exclusively responsible for the gene flow patterns observed in C. tanaceti.

The optimal scenario in the ABC analysis suggested that C. tanaceti was introduced to Victoria by incursion of a Tasmanian population. Invasion of Victoria was also supported by the lower gene diversity and allelic richness estimates of Victorian populations, a possible sign of the founding effect (Greenbaum et al. 2014; Szpiech et al. 2008). Commercial production of pyrethrum in Victoria only commenced in 2009, unlike in Tasmania where pyrethrum has been cultivated since 1980s. The fact that incursion into Victoria was selected against alternative scenarios with an unsampled ancestral population suggested Tasmanian populations could be native and not exotic.

TABLE 6. Summary of parameter estimates from analysis of Colletotrichum tanaceti population history

\begin{tabular}{lrrrrr}
\hline Parameter & Mean & Median & Mode & $\mathrm{q}_{0.050}$ & $\mathrm{q}_{0.950}$ \\
\hline $\mathrm{N} 1^{\mathrm{a}}$ & 5,460 & 5,270 & 5,010 & 1,940 & 9,430 \\
$\mathrm{~N}^{\mathrm{b}}$ & 7,440 & 7,710 & 7,900 & 4,290 & 9,740 \\
$\mathrm{t} 1^{\mathrm{c}, \mathrm{d}}$ & 427 & 412 & 427 & 110 & 815 \\
$\mathrm{t}^{\mathrm{c}, \mathrm{d}}$ & 606 & 520 & 486 & 226 & 1,130 \\
$\mathrm{t}^{\mathrm{c}, \mathrm{e}}$ & 602 & 555 & 501 & 233 & 1,110 \\
$\mathrm{~N}^{\mathrm{f}} \mathrm{b}^{\mathrm{f}}$ & 1,480 & 1,280 & 965 & 417 & 3,150 \\
\hline
\end{tabular}

a Effective population size of Victoria population.

b Effective population size of Tasmania population.

c Estimated number of generations from DIYABC modeling.

d Estimated sampling time from DIYABC modeling.

e Estimated splitting time from DIYABC modeling.

f Population size reduction due to bottleneck effect; demographic parameter estimations conducted under simulations for scenario 2 (invasion of Victoria). The priors and data were noninformative for determining the number of generations the founder effect retained ( $\mathrm{Db})$ (data not shown). 
Due to the high genotypic diversity of $C$. tanaceti populations within the short cultivation history of pyrethrum and the rejection of unknown ancestral population models that were tested, C. tanaceti could have expanded its host range (through either host jump/host shift) to pyrethrum from another host that was already present in Tasmania. Host expansion to previously unexposed hosts that are either genetically or ecologically similar to the previous host is a common mode of pathogen emergence (Burdon et al. 2009). Even though the data were uninformative for determining the duration of bottleneck effect, due to the large number of colonists from Tasmania as suggested by the ABC analysis, the Victorian population could have had a low bottleneck severity (Cornuet et al. 2008). The large effective population sizes suggested by the $\mathrm{ABC}$ analysis could be a product of interactions with the individuals on the other host since population size is determined by the collective population on all hosts than one (Burdon et al. 2009). An alternative host hypothesis is also in agreement with the failure to observe the sexual stage on pyrethrum plants in the field and also findings of Lelwala et al. (2019). The time period for the occurrence of the host expansion is unclear; it could also be recent since $C$. tanaceti was not reported in previous surveys of pyrethrum crop (Pethybridge et al. 2003, 2008b). Although other species of the host genus Tanacetum, such as T. parthenium and T. vulgare are present in Tasmania and Australia, Colletotrichum spp. have not been reported from these plant species. However, other Colletotrichum spp. have been reported in other genera of family Asteraceae such as Calendula, Carthamus, Chrysanthemum, Cosmos, Xanthium, and Zinnia (Hyde et al. 2009), that are present in pyrethrum growing regions of Australia. Therefore, the original host could have been such weed or ornamental plant that was already present in Australia and growing in close proximity to pyrethrum in fields. However, $C$. tanaceti isolates from different hosts are required to prove the host jump/shift hypothesis (Stukenbrock and McDonald 2008). Future studies on cross-host pathogenicity could refute or confirm these speculations.

Frequent recombination through sexual reproduction in $C$. tanaceti provides a means of generating new genotypes that could resist environmental changes and management practices (Correll and Gordon 1999). Asexual reproduction of C. tanaceti on the other hand can facilitate rapid multiplication of favorable genotypes (Giraud et al. 2008). Possibility of anthropogenic dispersal of propagules of $C$. tanaceti greatly increases the risk to pyrethrum as it can cause genotype flow which is a dispersion of linked coadapted set of alleles (McDonald and Linde 2002). Furthermore, a recent study on genomics of $C$. tanaceti revealed a high repeat content and thereby proposed a high mutational rate for C. tanaceti (Lelwala et al. 2019). Considering the above factors, C. tanaceti is likely to have a great evolutionary potential (McDonald and Linde 2002). Therefore, C. tanaceti poses a high risk to the Australian pyrethrum industry in the potential to develop tolerance to fungicides and by overcoming host resistance. Nevertheless, it is possible to manage anthropogenic gene and genotype flow with strict quarantine practices such as precluding or limiting exchange of equipment among pyrethrum paddocks. Disinfection and routine screening for pathogens in seeds for sowing are also recommended. Furthermore, crop rotation and establishing sound weed management policy could help maintain small population boundaries.

\section{ACKNOWLEDGMENTS}

We thank F. Hay (Cornell University, USA) and N. Vaghefi (University of Southern Queensland, Australia) for the 2013 isolate collection and S. Pilkington (Tasmanian Institute of Agriculture, University of Tasmania, Australia) and L. Head and A. Schipp (Botanical Resources Australia) and T. Groom of Wynyon Pty. Ltd. for assisting with the 2016-17 isolate collection. We also thank K. Pham and A. Hsu for genome library preparation and assembly, respectively.

\section{LITERATURE CITED}

Agapow, P. M., and Burt, A. 2001. Indices of multilocus linkage disequilibrium. Mol. Ecol. Notes 1:101-102.

Alahakoon, P. W., Sreenivasaprasad, S., Brown, A. E., and Mills, P. R. 1992. Selection of a genetic variant within Colletotrichum gloeosporioides isolates pathogenic on mango by passaging through wounded tomato fruits. Physiol. Mol. Plant Pathol. 41:227-240.

Ardlie, K. G., Kruglyak, L., and Seielstad, M. 2002. Patterns of linkage disequilibrium in the human genome. Nat. Rev. Genet. 3:299-309.

Barimani, M., Pethybridge, S. J., Vaghefi, N., Hay, F. S., and Taylor, P. W. J. 2013. A new anthracnose disease of pyrethrum caused by Colletotrichum tanaceti sp. nov. Plant Pathol. 62:1248-1257.

Barres, B., Carlier, J., Seguin, M., Fenouillet, C., Cilas, C., and Ravigne, V. 2012. Understanding the recent colonization history of a plant pathogenic fungus using population genetic tools and approximate Bayesian computation. Heredity 109:269-279.

Beaumont, M. A., Zhang, W., and Balding, D. J. 2002. Approximate Bayesian computation in population genetics. Genetics 162:2025-2035.

Benson, G. 1999. Tandem repeats finder: A program to analyze DNA sequences. Nucleic Acids Res. 27:573-580.

Bhat, B. K., and Menary, R. C. 1984. Pyrethrum production in Australia: Its past and present potential. J. Aust. Inst. Agric. Sci. 494:189-192.

Bhuiyan, M. A. H. B., Vaghefi, N., and Taylor, P. W. J. 2019. Ray blight of pyrethrum in Australia: A review of the current status and future opportunities. Plant Pathol. 68:620-627.

Bogacki, P., Keiper, F. J., and Oldach, K. H. 2010. Genetic structure of South Australian Pyrenophora teres populations as revealed by microsatellite analyses. Fungal Biol. 114:834-841.

Botstein, D., White, R. L., Skolnick, M., and Davis, R. W. 1980. Construction of a genetic linkage map in man using restriction fragment length polymorphisms. Am. J. Hum. Genet. 32:314-331.

Brewer, M. T., Frenkel, O., and Milgroom, M. G. 2012. Linkage disequilibrium and spatial aggregation of genotypes in sexually reproducing populations of Erysiphe necator. Phytopathology 102:997-1005.

Brown, J. K. M. 1994. Chance and selection in the evolution of barley mildew. Trends Microbiol. 2:470-475.

Brown, J. K. M. 1995. Pathogens' responses to the management of disease resistance genes. Pages 75-102 in: Advances in Plant Pathology. Vol. 11. J. H. Andrews and I. C. Tommerup, eds. Academic Press, New York.

Brown, J. K. M. 1999. The evolution of sex and recombination in fungi. Pages 73-95 in: Structure and Dynamics of Fungal Populations. J. J. Worrall, ed. Springer, Dordrecht, The Netherlands.

Brown, J. K. M., and Wolfe, M. S. 1990. Structure and evolution of a population of Erysiphe graminis f. sp. hordei. Plant Pathol. 39:376-390.

Bruvo, R., Michiels, N. K., D'Souza, T. G., and Schulenburg, H. 2004. A simple method for the calculation of microsatellite genotype distances irrespective of ploidy level. Mol. Ecol. 13:2101-2106.

Burdon, J. J., Thrall, P. H., and Ericson, L. 2009. Plant Pathogens and Disease: Newly Emerging Diseases. Pages 647-654 in: Encyclopedia of Microbiology. Elsevier, Oxford.

Burt, A., Carter, D. A., Koenig, G. L., White, T. J., and Taylor, J. W. 1996. Molecular markers reveal cryptic sex in the human pathogen Coccidioides immitis. Proc. Natl. Acad. Sci. 93:770-773.

Camacho, C., Coulouris, G., Avagyan, V., Ma, N., Papadopoulos, J., Bealer, K., and Madden, T. L. 2009. BLAST+: Architecture and applications. BMC Bioinformatics 10:421.

Carbone, I., and Kohn, L. 2004. Inferring Process from Pattern in Fungal Population Genetics. Appl. Mycol. Biotechnol. 4:29-58.

Casida, J. E., and Quistad, G. B. 1995. Pyrethrum Flowers: Production, Chemistry, Toxicology, and Uses. Oxford University Press, New York.

Cornuet, J.-M., Pudlo, P., Veyssier, J., Dehne-Garcia, A., Gautier, M., Leblois, R., Marin, J.-M., and Estoup, A. 2014. DIYABC v2.0: A software to make approximate Bayesian computation inferences about population history using single nucleotide polymorphism, DNA sequence and microsatellite data. Bioinformatics 30:1187-1189.

Cornuet, J. M., Santos, F., Beaumont, M. A., Robert, C. P., Marin, J. M., Balding, D. J., Guillemaud, T., and Estoup, A. 2008. Inferring population history with DIY ABC: A user-friendly approach to approximate Bayesian computation. Bioinformatics 24:2713-2719.

Correll, J. C., and Gordon, T. R. 1999. Population structure of ascomycetes and deuteromycetes. Pages 225-250 in: Structure and Dynamics of Fungal Populations. J. J. Worrall, ed. Springer, Dordrecht, The Netherlands.

Currie-Fraser, E., Shah, P., and True, S. 2010. Data analysis using GeneMapper ${ }^{\circledR}$ v4.1: Comparing the Newest Generation of GeneMapper 
Software to Legacy Genescan ${ }^{\circledR}$ and Genotyper ${ }^{\circledR}$ Software. J. Biomol. Tech. JBT 21:S31.

de Meeûs, T., and Balloux, F. 2004. Clonal reproduction and linkage disequilibrium in diploids: A simulation study. Infect. Genet. Evol. 4:345-351.

Debuchy, R., and Turgeon, B. G. 2006. Mating-type structure, evolution, and function in Euascomycetes. Pages 293-323 in: Growth, Differentiation and Sexuality. Vol. 1. U. Kües and R. Fischer, eds. Springer, Berlin, Heidelberg.

Dyer, P. S., and Paoletti, M. 2005. Reproduction in Aspergillus fumigatus: Sexuality in a supposedly asexual species? Med. Mycol. 43:S7-S14.

Excoffier, L., Smouse, P. E., and Quattro, J. M. 1992. Analysis of molecular variance inferred from metric distances among DNA haplotypes: Application to human mitochondrial DNA restriction data. Genetics 131:479-491.

Giraud, T., Enjalbert, J., Fournier, E., Delmotte, F., and Dutech, C. 2008. Population genetics of fungal diseases of plants. Parasite 15:449-454.

Golan, J. J., and Pringle, A. 2017. Long-distance dispersal of fungi. Page 309-333 in: The Fungal Kingdom. J. Heitman, B. Howlett, P. Crous, E. Stukenbrock, T. James, and N. Gow, eds. ASM Press, Washington, DC.

Greenbaum, G., Templeton, A. R., Zarmi, Y., and Bar-David, S. 2014. Allelic richness following population founding events-A stochastic modeling framework incorporating gene flow and genetic drift. PLoS One 9:e115203.

Groenewald, M., Linde, C. C., Groenewald, J. Z., and Crous, P. W. 2008. Indirect evidence for sexual reproduction in Cercospora beticola populations from sugar beet. Plant Pathol. 57:25-32.

Grünwald, N. J., Goodwin, S. B., Milgroom, M. G., and Fry, W. E. 2003. Analysis of genotypic diversity data for populations of microorganisms. Phytopathology 93:738-746.

Hay, F. S., Gent, D. H., Pilkington, S. J., Pearce, T. L., Scott, J. B., and Pethybridge, S. J. 2015. Changes in distribution and frequency of fungi associated with a foliar disease complex of pyrethrum in Australia. Plant Dis. 99:1227-1235.

Hey, J. 2010. Isolation with migration models for more than two populations. Mol. Biol. Evol. 27:905-920.

Hey, J., and Nielsen, R. 2007. Integration within the Felsenstein equation for improved Markov chain Monte Carlo methods in population genetics. Proc. Natl. Acad. Sci. USA 104:2785-2790.

Holleley, C. E., and Geerts, P. G. 2009. Multiplex Manager 1.0: A crossplatform computer program that plans and optimizes multiplex PCR. Biotechniques 46:511-517.

Holm, S. 1979. A simple sequentially rejective multiple test procedure. Scand. J. Stat. 6:65-70.

Hoyland, L. and van Graver, D. 2010. R and D transforms pyrethrum technology. Agric. Sci. 22:21-23.

Hyde, K., Cai, L., Cannon, P., Crouch, J. A., Crous, P., Damm, U., Goodwin, P. H., Chen, H., Johnston, P., Jones, E. B. G., Liu, Z. Y., McKenzie, E., Moriwaki, J., Noireung, P., Pennycook, S., Pfenning, L. H., Prihastuti, H., Sato, T., Shivas, R., and Zhang, J. Z. 2009. Colletotrichum-names in current use. Fungal Diversity 39:147-182.

Ivens, A. B. F., van de Sanden, M., and Bakker, J. 2012. MLGsim 2.0: Updated software for detecting clones from micro satellite data using a simulation approach. Pages 107-111 in: The Evolutionary Ecology of Mutualism. U. O. Groningen, ed. Ph.D. thesis. University of Groningen.

Jombart, T. 2008. Adegenet: A R package for the multivariate analysis of genetic markers. Bioinformatics 24:1403-1405.

Jombart, T., Devillard, S., and Balloux, F. 2010. Discriminant analysis of principal components: A new method for the analysis of genetically structured populations. BMC Genet. 11:94.

Kamvar, Z. N., Brooks, J. C., and Grünwald, N. J. 2015. Novel R tools for analysis of genome-wide population genetic data with emphasis on clonality. Front. Genet. 6:208.

Kamvar, Z. N., Tabima, J. F., and Grünwald, N. J. 2014. Poppr: An R package for genetic analysis of populations with clonal, partially clonal, and/or sexual reproduction. PeerJ 2:e281.

Katsuda, Y. 1999. Development of and future prospects for pyrethroid chemistry. Pestic. Sci. 55:775-782.

Kimura, M., and Ohta, T. 1978. Stepwise mutation model and distribution of allelic frequencies in a finite population. Proc. Natl. Acad. Sci. USA 75: 2868-2872.

Koressaar, T., and Remm, M. 2007. Enhancements and modifications of primer design program Primer3. Bioinformatics 23:1289-1291.

Kuhner, M. K., and Smith, L. P. 2007. Comparing likelihood and Bayesian coalescent estimation of population parameters. Genetics 175:155-165.

Lelwala, R. V., Korhonen, P. K., Young, N. D., Scott, J. B., Ades, P. K., Gasser, R. B., and Taylor, P. W. J. 2019. Comparative genome analysis indicates high evolutionary potential of pathogenicity genes in Colletotrichum tanaceti. PLoS One 14:e212248.

Linde, C. C., Zhan, J., and McDonald, B. A. 2002. Population structure of Mycosphaerella graminicola: from lesions to continents. Phytopathology 92:946-955.

Ludwig, J. A., and Reynolds, J. F. 1988. Statistical Ecology: A Primer on Methods and Computing. John Wiley and Sons, Inc., New York.
Manly, B. F. J. 1985. The Statistics of Natural Selection on Animal Populations. Springer, Dordrecht, The Netherlands.

Marko, P. B., and Hart, M. W. 2011. The complex analytical landscape of gene flow inference. Trends Ecol. Evol. 26:448-456.

McDonald, B. A. 1997. The population genetics of fungi: Tools and techniques. Phytopathology 87:448-453.

McDonald, B. A., and Linde, C. 2002. Pathogen population genetics, evolutionary potential, and durable resistance. Annu. Rev. Phytopathol. 40: 349-379.

McDonald, B. A., and Stukenbrock, E. H. 2016. Rapid emergence of pathogens in agro-ecosystems: Global threats to agricultural sustainability and food security. Philosophical Transactions of the Royal Society B. Biol. Sci. 371:20160026.

McDonald, M. J., Rice, D. P., and Desai, M. M. 2016. Sex speeds adaptation by altering the dynamics of molecular evolution. Nature 531:233-236.

Menat, J., Armstrong-Cho, C., and Banniza, S. 2016. Lack of evidence for sexual reproduction in field populations of Colletotrichum lentis. Fungal Ecol. 20:66-74.

Menat, J., Cabral, A. L., Vijayan, P., Wei, Y., and Banniza, S. 2012. Glomerella truncata: Another Glomerella species with an atypical mating system. Mycologia 104:641-649.

Metzenberg, R. L., and Glass, N. L. 1990. Mating type and mating strategies in Neurospora. BioEssays 12:53-59.

Milgroom, M. G. 1996. Recombination and the multilocus structure of fungal populations. Annu. Rev. Phytopathol. 34:457-477.

Nei, M. 1973. Analysis of gene diversity in subdivided populations. Proc. Natl. Acad. Sci. USA 70:3321-3323.

Orsini, L., Mergeay, J., Vanoverbeke, J., and De Meester, L. 2013a. The role of selection in driving landscape genomic structure of the waterflea Daphnia magna. Mol. Ecol. 22:583-601.

Orsini, L., Vanoverbeke, J., Swillen, I., Mergeay, J., and De Meester, L. 2013 b. Drivers of population genetic differentiation in the wild: Isolation by dispersal limitation, isolation by adaptation and isolation by colonization. Mol. Ecol. 22:5983-5999.

Peakall, R., and Smouse, P. E. 2012. GenAlEx 6.5: Genetic analysis in Excel. Population genetic software for teaching and research-an update. Bioinformatics 28:2537-2539.

Pearce, T. L., Scott, J. B., Pilkington, S. J., Pethybridge, S. J., and Hay, F. S. 2019. Evidence for sexual recombination in Didymella tanaceti populations, and their evolution over spring production in Australian pyrethrum fields. Phytopathology 109:155-168.

Peterson, M. A., and Denno, R. F. 1998. The influence of dispersal and diet breadth on patterns of genetic isolation by distance in phytophagous insects. Am. Nat. 152:428-446.

Pethybridge, S. J., Hay, F. S., Esker, P. D., Gent, D. H., Wilson, C. R., Groom, T., and Nutter, F. W., Jr. 2008b. Diseases of pyrethrum in Tasmania: Challenges and prospects for management. Plant Dis. 92:1260-1272.

Pethybridge, S. J., Hay, F. S., and Groom, T. 2003. Seasonal fluctuations in fungi associated with pyrethrum foliage in Tasmania. Australas. Plant Pathol. 32:223-230.

Pethybridge, S. J., Jones, S. J., Shivas, R. G., Hay, F. S., Wilson, C. R., and Groom, T. 2008a. Tan spot: A new disease of pyrethrum caused by Microsphaeropsis tanaceti sp. nov. Plant Pathol. 57:1058-1065.

Pompanon, F., Bonin, A., Bellemain, E., and Taberlet, P. 2005. Genotyping errors: Causes, consequences and solutions. Nat. Rev. Genet. 6: 847-859.

R Core Team. 2015. R: A language and environment for statistical computing. R Foundation for Statistical Computing, Vienna, Austria.

Rodriguez-Guerra, R., Ramirez-Rueda, M. T., Cabral-Enciso, M., Garcia-Serrano, M., Lira-Maldonado, Z., Guevara-Gonzalez, R. G., Gonzalez-Chavira, M., and Simpson, J. 2005. Heterothallic mating observed between Mexican isolates of Glomerella lindemuthiana. Mycologia 97:793-803.

Rogers, S. O., and Rogers, M. A. M. 1999. Gene flow in fungi. Pages 97-121 in: Structure and Dynamics of Fungal Populations. J. J. Worrall, ed. Springer, Dordrecht, The Netherlands.

Scott, J. B., Gent, D. H., Pearce, T. L., Pethybridge, S. J., Pilkington, S. J., and Hay, F. S. 2017. Mycoflora associated with pyrethrum seed and the integration of seed steam treatment into foliar disease management strategies. Plant Dis. 101:1874-1884.

Simpson, E. H. 1949. Measurement of diversity. Nature 163:688.

Slatkin, M. 2008. Linkage disequilibrium-understanding the evolutionary past and mapping the medical future. Nat. Rev. Genet. 9:477-485.

Smith, J. M., Smith, N. H., O’Rourke, M., and Spratt, B. G. 1993. How clonal are bacteria? Proc. Natl. Acad. Sci. 90:4384-4388.

Spurgin, L. G., Illera, J. C., Jorgensen, T. H., Dawson, D. A., and Richardson, D. S. 2014. Genetic and phenotypic divergence in an island bird: Isolation by distance, by colonization or by adaptation? Mol. Ecol. 23:1028-1039. 
Stenberg, P., Lundmark, M., and Saura, A. 2003. Mlgsim: A program for detecting clones using a simulation approach. Mol. Ecol. Notes 3:329-331.

Stukenbrock, E. H., and McDonald, B. A. 2008. The origins of plant pathogens in agro-ecosystems. Annu. Rev. Phytopathol. 46:75-100.

Sutton, T., and Shane, W. 1983. Epidemiology of the perfect stage of Glomerella cingulata on apples. Phytopathology 73:1179-1183.

Szpiech, Z. A., Jakobsson, M., and Rosenberg, N. A. 2008. ADZE: A rarefaction approach for counting alleles private to combinations of populations. Bioinformatics 24:2498-2504.

Taylor, J. W., Geiser, D. M., Burt, A., and Koufopanou, V. 1999. The evolutionary biology and population genetics underlying fungal strain typing. Clin. Microbiol. Rev. 12:126-146.
Untergasser, A., Cutcutache, I., Koressaar, T., Ye, J., Faircloth, B. C., Remm, M., and Rozen, S. G. 2012. Primer3-new capabilities and interfaces. Nucleic Acids Res. 40:e115.

Vaghefi, N., Hay, F. S., Ades, P. K., Pethybridge, S. J., Ford, R., and Taylor, P. W. J. 2014. Rapid changes in the genetic composition of Stagonosporopsis tanaceti population in Australian pyrethrum fields. Phytopathology 105:358-369.

Vaillancourt, L., Du, M., Wang, J., Rollins, J., and Hanau, R. 2000. Genetic analysis of cross fertility between two self-sterile strains of Glomerella graminicola. Mycologia 92:430-435.

Wright, S. 1943. Isolation by distance. Genetics 28:114-138

Yeh, F. C., and Boyle, T. J. B. 2016. Population genetic analysis of codominant and dominant markers and quantitative traits. Belgian J. Bot. 129:157-163. 